\title{
A Focused Review on Recent Advances in the Diagnosis and Treatment of Viral Hepatitis
}

\author{
Wei Zhang ${ }^{\mathrm{a}}$, Mahmoud Aryan ${ }^{\mathrm{b}}$, Steve Qian ${ }^{\mathrm{c}}$, Roniel Cabrera ${ }^{\mathrm{a}}$, Xiuli Liu ${ }^{\mathrm{d}, \mathrm{e}}$
}

\begin{abstract}
The global burden of viral hepatitis remains substantial despite advances in antiviral therapy and effective vaccines. There are five hepatitis viruses (hepatitis A, B, C, D, and E). Mortality related to hepatitis B virus and hepatitis $\mathrm{C}$ virus infections is among the top four global infectious diseases, together with human immunodeficiency virus infection, malaria, and tuberculosis. Of those deaths, approximately $47 \%$ are attributable to hepatitis B virus, $48 \%$ to hepatitis $C$ virus and the remainder to hepatitis A virus and hepatitis $\mathrm{E}$ virus. Ending hepatitis epidemics as a major public health threat is feasible with the tools and approaches currently available. Effective vaccines are available for preventing viral hepatitis $\mathrm{A}, \mathrm{B}$ and $\mathrm{E}$ infections. New oral, well-tolerated treatment regimens for chronic hepatitis $\mathrm{C}$ patients can achieve cure rates of over $90 \%$. Effective treatment is also available for people with chronic hepatitis B virus infection; although for most people such treatment needs to be long-term, and recent advanced aim at a "functional cure" of hepatitis B. In this review article, we discuss the most recent advances of the diagnosis and treatment of viral hepatitis.
\end{abstract}

Keywords: Cirrhosis; Direct antiviral agents; Hepatitis A; Hepatitis B; Hepatic C; Hepatocellular carcinoma; Hepatitis D; Hepatitis E

\section{Introduction}

The global burden of viral hepatitis remains substantial despite major advances in prevention and treatment in recent years. Viral hepatitis caused 1.34 million deaths in 2015, which is on a par with deaths caused by tuberculosis, malaria, and human

Manuscript submitted April 28, 2021, accepted June 11, 2021

Published online June 19, 2021

aDivision of Gastroenterology and Hepatology, Department of Internal Medicine, University of Florida, Gainesville, FL, USA

bepartment of Medicine, University of Alabama at Birmingham, Birmingham, AL, USA

'Department of Internal Medicine, University of Florida, Gainesville, FL, USA ${ }^{\mathrm{d} D e p a r t m e n t}$ of Pathology, Immunology and Laboratory Medicine, University of Florida, Gainesville, FL, USA

${ }^{\text {e}}$ Corresponding Author: Xiuli Liu, Department of Pathology, Immunology and Laboratory Medicine, University of Florida, PO Box 100275, 1600 SW Archer Road, Gainesville, FL 32610, USA. Email: xiuliliu@ufl.edu immunodeficiency virus (HIV) [1]. Five liver specific (hepatotropic) viruses are responsible for most cases of viral hepatitis. These are the hepatitis A virus (HAV), hepatitis B virus (HBV), hepatitis $\mathrm{C}$ virus (HCV), hepatitis D virus (HDV) and hepatitis E virus (HEV). Of these, HBV and HCV cause $96 \%$ of the mortality from viral hepatitis. The main liver complications include cirrhosis and hepatocellular carcinoma (HCC). It was reported that in 2015, an estimated 257 million people were living with chronic HBV infection, and 71 million people with chronic $\mathrm{HCV}$ infection [2, 3]. In 2016, the World Health Organization (WHO) committed to eliminating viral hepatitis as a public health threat by 2030 (defined as a $65 \%$ reduction in mortality and a $90 \%$ reduction in incidence compared with the 2015 baseline) [2, $3]$. However, the goal is challenging due to lack of diagnosis in most patients and limited access to treatment. The epidemiology, risk for chronicity, risk for liver complications, and treatments vary considerably in the five viruses. Acute infection occurs with all five viruses, while chronic infection occurs mainly in HBV, HCV and HDV. This review provides a review of recent advances in the diagnosis and treatment of viral hepatitis focusing on rapid diagnostic modalities, new treatments developed and currently being tested in clinical trials, development of vaccines to treat chronic hepatitis $\mathrm{B}(\mathrm{CHB})$ and use of vaccine to prevent HEV in some parts of the world.

\section{HAV}

HAV is one of the most common infectious causes of acute hepatitis worldwide. According to the WHO, there are an estimated 1.4 million cases every year [4]. Transmission occurs primarily through fecal-oral routes via contamination of food or water, or through close contact with infected persons. Historically, epidemics have occurred in developing countries in areas of poor sanitation. However, owing to the efficacy of the HAV vaccine as well as improved sanitary measures, the epidemiology of HAV infection has seen a shift in recent years [5]. Increasingly, epidemics now occur in high-risk adults, namely the homeless, illicit drug users, and men who have sex with men. Since 2016, over 31,000 cases have been documented in this population in the United States alone [6].

\section{Diagnosis}

Definitive diagnosis of acute hepatitis A infection has clas- 
sically been made by detection of serum immunoglobulin $\mathrm{M}$ (IgM) anti-HAV antibodies via enzyme immunoassay (EIA). However, as EIA testing requires infrastructure and is timeconsuming, there has been increased interest in point of care (POC) testing. More rapid diagnostic testing could potentially facilitate identification of susceptible individuals during outbreaks, as well as provide those in resource-poor areas a means for diagnosis. A study in Brazil showed that a commercial rapid immunochromatographic test for HAV IgM had $81 \%$ sensitivity and $100 \%$ specificity [7]. Another study on 5,438 patients in Puerto Rico demonstrated efficacy of a rapid salivary test for HAV IgG, with sensitivity comparable to human plasma analyses [8].

\section{Treatment}

As hepatitis A is typically self-limiting, treatment is primarily supportive. Up to $10-15 \%$ of patients will have relapsing illness up to 6 months after resolution of initial illness. However, hepatitis A does not progress to chronic liver disease and less than $1 \%$ of cases lead to acute liver failure [9]. In those who develop acute liver failure, however, approximately $30 \%$ will require transplant or die. Currently, there are no approved antiviral therapies for HAV infection, although one 2018 study has shown that sofosbuvir inhibits HAV replication in vitro [10].

\section{Vaccination and prophylaxis}

Vaccination is recommended for all children 12 months and older, travelers to endemic regions, those with chronic liver disease, men who have sex with men, and illicit drug users. In those with suspected exposure, post-exposure prophylaxis with the vaccine is recommended over the immune globulin [11]. However, for patients 41 years and older, children less than 12 months of age, and the immunocompromised, the immunoglobulin remains recommended due to increased risk for adverse effects with the vaccine, and limited data on efficacy for the vaccine [12].

\section{HBV}

CHB infection is a common cause of liver disease globally, with a disproportionately high burden in the African Region and the Western Pacific Region. Although vaccination has substantially reduced HBV transmission, coverage with the initial birth dose vaccination was still low at 39\%. In addition, despite affordable and effective treatment, only $9 \%$ of people infected with HBV were diagnosed in 2015, and only $8 \%$ of those meeting criteria for therapy were on treatment $[13,14]$.

HBV is a partially double-stranded hepatotropic DNA virus that belongs to the Hepadnaviridae family. The presence of the HBV surface antigen (HBsAg) establishes the diagnosis of $\mathrm{HBV}$. Chronic infection is defined by the presence of $\mathrm{HBsAg}$ in the serum for over 6 months. In 2015, the global prevalence of CHB infection was $3.5 \%$ with the highest areas in the African $(6.1 \%)$ and Western Pacific regions (6.2\%) [15]. In most countries where HBV is endemic, perinatal transmission is the most important cause of infection. The risk of developing chronic HBV infection after perinatal exposure was $90 \%$ in newborns of HBV-infected mothers. Other routes of transmission include direct contact with infected blood, unprotected sex, use of illegal drugs, or needles and other medical/dental equipments or procedures that are contaminated or not sterile. HBV screening is recommended in high-risk groups (Table 1).

\section{Diagnosis}

Traditional serological tests include $\mathrm{HBsAg}$, hepatitis B E antigen ( $\mathrm{HBeAg}$ ), hepatitis B core antibody (anti-HBc), and hepatitis B DNA level. The IgM subtype of anti-HBc is indicative of acute infection or reactivation, whereas the $\mathrm{IgG}$ subtype is indicative of chronic infection or previous infection. Quantitative HBsAg, although not commercially available in the United States, was found to predict HBsAg seroclearance after the cessation of antiviral treatment when the serum HBsAg level is $<100$ to $200 \mathrm{IU} / \mathrm{mL}$. Hepatitis B core-related antigen (HBcrAg) is a novel biomarker that has an important role in CHB. HBcrAg is a common amino acid sequence shared by hepatitis $\mathrm{B}$ core antigen, $\mathrm{HBeAg}$, and a truncated $22 \mathrm{kDa}$ precore protein $(\mathrm{p} 22 \mathrm{Cr})$ [16]. It was reported to correlate with the levels and transcriptional activities of intrahepatic covalently closed circular DNA (cccDNA). A complete $\mathrm{HBV}$ cure is currently not possible because of the presence of the cccDNA. HBcrAg has been also shown to correlate with intrahepatic viral RNA levels in Asian patients treated with nucleos(t)ide analog (NA) [16]. Hence, HBcrAg could be used as a surrogate of cccDNA in the liver. It can be useful in the evaluation of new antiviral therapies aiming at a functional cure of HBV infection either by directly or indirectly targeting the intrahepatic cccDNA pool. Another report showed that patients with persistently high on-treatment HBcrAg levels were more likely to develop HCC despite sustained viral suppression via long-term NA treatment, indicating that $\mathrm{HBcrAg}$ could potentially be used to predict risk of malignancy in CHB patients.

Early diagnosis remains a significant challenge of HBV infection especially in high-risk groups and in resource-limited regions. There is unmet need to scale up screening for HBV in such population. The barriers of early diagnosis include limited access to healthcare, cost, and limited laboratory resources. This is especially important in many low-resource and geographically isolated regions. POC tests (also known as rapid diagnostic tests, RDTs) are simplified tests that have the potential to overcome the barriers [17]. POCs require only small amounts of body fluids (e.g., a finger-prick blood sample), are easy to use with minimal training, take short turn-around time (TAT, 20 - $30 \mathrm{~min}$ ) and may achieve same-day "test and treat". A key benefit of POCs is to engage hard-to-reach communities for testing, such as using HBsAg POC tests for HBV screening in remote areas, or harm reduction programs. So far, only three POCs for detecting HBsAg have been prequalified by 
Table 1. High-Risk Groups for Hepatitis Viruses

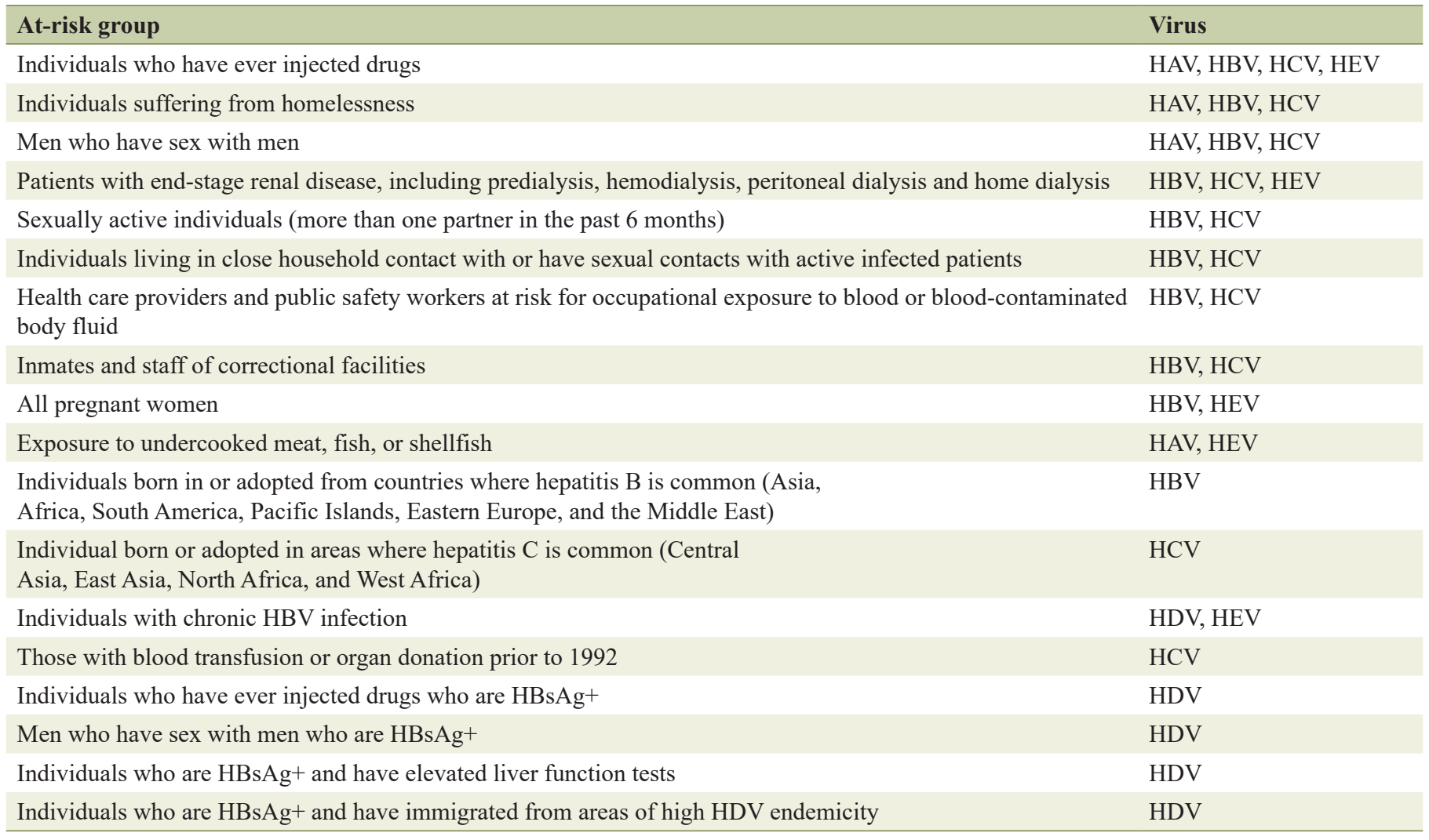

HAV: hepatitis A virus; HBV: hepatitis B virus; HCV: hepatitis C virus; HDV: hepatitis D virus; HEV: hepatitis E virus; HBsAg: HBV surface antigen.

the WHO. Typically, POC tests have lower accuracy than traditional laboratory-based tests. However, recent studies show that the sensitivity and specificity have been excellent at over $90 \%$ [17]. Other limitations of POCs include issues regarding regulatory process, procurement and storage management for POC tests, as well as costs when implementing POCs for HBV in different settings.

\section{Treatment}

Currently approved treatments of CHB include two formulations of interferon, standard and pegylated, and six NAs [18]. Of these, pegylated interferon alpha (Peg-IFN- $\alpha$ ), entecavir (ETV), tenofovir disoproxil fumarate (TDF), and tenofovir alafenamide (TAF) are recommended as first-line treatment. While Peg-IFN is rarely used, the three NAs are the preferred choice. TAF is a new oral prodrug of tenofovir (TFV), a nucleotide analog that inhibits reverse transcription of $\mathrm{HBV}$ DNA. TAF has greater plasma stability than TDF, which can enhance delivery of the active metabolite, tenofovir diphosphate, to hepatocytes more efficiently than TDF, thus reducing the circulatory levels of tenofovir. The two large, ongoing, randomized, double-blind, international phase III trials (GSUS-320-0110 and GS-US-320-0108) both showed that TAF had similar antiviral efficacy in suppressing HBV replication compared to TDF, did not induce virologic resistance, but was associated with significantly less bone and renal toxicity in both $\mathrm{HBeAg}+$ and $\mathrm{HBeAg}-\mathrm{CHB}$ patients after 2 years of treatment $[19,20]$.

\section{Treatment guidelines}

Current guidelines recommend antiviral treatment in patients with cirrhosis and detectable viremia, regardless of alanine aminotransferase (ALT) or HBV DNA levels. For non-cirrhotic patients, all guidelines recommend treatment if they are at immune active phase which indicates ongoing liver injury and has the highest risk of developing cirrhosis. However, there is slight difference between them. The European Association for the Study of the Liver (EASL) guidelines use HBV DNA cutoff of 2,000 IU/mL regardless of HBeAg status, whereas the American Association for the Study of Liver Diseases (AASLD) and the Asian Pacific Association for the Study of the Liver (APASL) guidelines suggest cutoff of $20,000 \mathrm{IU} / \mathrm{mL}$ for $\mathrm{HBeAg}$-positive and 2,000 $\mathrm{IU} / \mathrm{mL}$ for $\mathrm{HBeAg}$-negative patients [18, 21-23]. The AASLD and APASL guidelines use ALT $>2$ upper limit normal (ULN) or histologic evidence of moderate or severe necroinflammation or significant fibrosis for initiating treatment, while the EASL guidelines use ALT > ULN with histologic evidence of moderate necroinflammation and/or moderate fibrosis or liver stiffness $>9 \mathrm{kPa}$ or if histology is not available, ALT $>2 \mathrm{ULN}$ and HBV DNA $>20,000$ 
Table 2. Guidelines for Chronic Hepatitis B Treatment

\begin{tabular}{|c|c|c|c|c|}
\hline & $\begin{array}{l}\text { HBV } \\
\text { cirrhosis }\end{array}$ & $\begin{array}{l}\text { HBV non-cir- } \\
\text { rhotic HBeAg+ }\end{array}$ & $\begin{array}{l}\text { HBV non-cir- } \\
\text { rhotic HBeAg- }\end{array}$ & Other indications to initiate treatment \\
\hline EASL & Treat & $\begin{array}{l}\text { HBV DNA cutoff } \\
\text { of } 2,000 \mathrm{IU} / \mathrm{mL}\end{array}$ & $\begin{array}{l}\text { HBV DNA cutoff } \\
\text { of } 2,000 \mathrm{IU} / \mathrm{mL}\end{array}$ & $\begin{array}{l}\text { ALT }>40 \mathrm{U} / \mathrm{L} \text { with histologic evidence of moderate } \\
\text { necroinflammation and/or moderate fibrosis } \\
\text { ALT }>40 \mathrm{U} / \mathrm{L} \text { with histologic evidence of moderate } \\
\text { necroinflammation and/or liver stiffness }>9 \mathrm{kPa} \\
\text { ALT }>80 \mathrm{U} / \mathrm{L} \text { and } \mathrm{HBV} \text { DNA }>20,000 \mathrm{IU} / \mathrm{mL} \text {, if histology is not available. }\end{array}$ \\
\hline AASLD & Treat & $\begin{array}{l}\text { HBV DNA cutoff } \\
\text { of } 20,000 \mathrm{IU} / \mathrm{mL}\end{array}$ & $\begin{array}{l}\text { HBV DNA cutoff } \\
\text { of } 2,000 \mathrm{IU} / \mathrm{mL}\end{array}$ & $\begin{array}{l}\text { ALT }>70 \mathrm{U} / \mathrm{L} \text { (for male) and ALT }>50 \mathrm{U} / \mathrm{L} \text { (for female) or } \\
\text { histologic evidence of moderate or severe necroinflammation } \\
\text { or significant fibrosis for initiating treatment }\end{array}$ \\
\hline
\end{tabular}

HBV: hepatitis B virus; HBeAg: hepatitis B E antigen; ALT: alanine aminotransferase; EASL: European Association for the Study of the Liver; AASLD: American Association for the Study of Liver Diseases.

$\mathrm{IU} / \mathrm{mL}$ to initiate treatment. The AASLD guidelines used the cutoff ULN for ALT at $35 \mathrm{U} / \mathrm{L}$ for male patients and $25 \mathrm{U} / \mathrm{L}$ for female patients, while the EASL and APASL use $40 \mathrm{U} / \mathrm{L}$ as a cutoff for both genders. The EASL, AASLD, and APASL guidelines for treating chronic HBV are summarized in Table 2 .

\section{Conventional antivirals}

Antiviral therapy is effective in suppressing viral replication, reversing hepatic inflammation and fibrosis, preventing progression to cirrhosis and liver failure, and decreasing risk of $\mathrm{HCC}$ and liver-related mortality. However, it has limitations in that it does not eradicate cccDNA or integrated HBV DNA with low rate of HBsAg loss particularly with non-A genotypes. In addition, long-term therapy may reduce but not eliminate the risk of liver cancer. Therefore, new therapies for HBV that can achieve sustained suppression and HBsAg loss after a limited course of therapy are needed $[24,25]$.

There are different definitions of HBV cure. Partial cure is defined as normalization of liver enzymes and suppression of HBV DNA without loss of HBsAg. This could be achieved by current antiviral therapy, however, requires long-term therapy and does not eliminate the risk of malignancy. Complete cure is defined as loss of HBsAg with undetectable cccDNA and integrated HBV DNA. Complete cure is difficult to achieve as the HBV DNA is integrated into hepatocytes, unless patients are being treated early before integration has occurred. Functional cure is defined as loss of HBsAg with detectable but inactive cccDNA and integrated HBV DNA [26, 27]. This is considered as more reasonable and realistic goal of HBV cure. Currently, presumed pathways to achieve functional cure include therapies that can inhibit viral replication, lower viral antigen burden, and boost immune response. In the past few years, due to a better understanding of viral life cycle and viral pathogenetic mechanisms, new therapeutic viral targets have been identified that resulted in developments of several compounds.

\section{New therapeutic strategies}

\section{1) RNA interference (RNAi)}

RNAi is a highly specific and efficient method of post-transcriptional gene silencing [28]. The synthetic small interfering RNA (siRNA) can be used to inhibit HBV replication resulting in decreased expression of $\mathrm{HBsAg}$ and $\mathrm{HBeAg}$ (tolerogenic antigens). The main limitation of this drug is the route of delivery as it is digested rapidly in the gut and intravenous injection can cause infusion reaction. Recently subcutaneous injections that target the liver were developed. Arrowhead's siRNA ARC520 was the first siRNA drug designed to reduce all RNA transcripts derived from covalently closed circular DNA, leading to a reduction in viral antigens and HBV DNA. In two randomized phase 2 multidose studies in $\mathrm{HBeAg}$ positive and $\mathrm{HBeAg}$ negative, NA-experienced patients with $\mathrm{CHB}$ infection, multiple doses of $2 \mathrm{mg} / \mathrm{kg}$ ARC520 significantly reduced HBsAg in both patient groups compared to placebo, and antigen reductions were sustained for a long period of time; however, absolute reductions were generally moderate [29]. Due to safety concern of the drug delivery system, the clinical trials of ARC520 were terminated. A modified RNAi, JNJ-3989 (formerly ARO-HBV), was developed to contain two RNAi that are both conjugated to $\mathrm{N}$-acetyl galactosamine to facilitate uptake by the liver. In a recent phase 2 study of $40 \mathrm{HBeAg}+$ or $\mathrm{HBeAg}$ - NA-naive or NA-experienced patients, JNJ-3989 at a dose of $100-400$ $\mathrm{mg}$ in combination with an NA was well tolerated. The maximum reduction in $\mathrm{HBsAg}>1 \log _{10} \mathrm{IU} / \mathrm{mL}$ was achieved in 98\% patients and 17 (43\%) patients had sustained HBsAg suppression at 9 months after the last dose of JNJ-3989 [30]. Liver-targeted antisense oligonucleotides, RNA destabiliziers and locked nucleic acids are alternative approaches to blocking viral protein expression. In a recent phase 2 randomized clinical trial in $66 \mathrm{HBeAg}+$ and $\mathrm{HBeAg}-\mathrm{NA}$ suppressed patients, GSK3389404 at a maximum weekly dose of $120 \mathrm{mg}$ resulted in an average $\mathrm{HBsAg}$ reduction of 0.75 
$\log \mathrm{IU} / \mathrm{mL}$ compared to $0.02 \log \mathrm{IU} / \mathrm{mL}$ in placebo by day 85 without major side effects $[31,32]$.

\section{2) Core protein allosteric modulators (CpAMs)}

HBV core protein is key in packing pgRNA and interaction with HBsAg. CpAMs were developed to cause aberrant noncapsid polymers or assembly of empty capsids, thus decreasing the viral replication. Two classes of CpAMs have been discovered: the heteroaryldihydropyrimidines (HAPs) (type I CpAMs or CpAM-A) and the phenylpropenamides (PPAs) (type II CpAMs or CpAM-N). In a phase 1 study, a type I CpAM RO7049389 administration resulted in a robust decline in median HBV DNA (2.7 to $3.0 \log 10 \mathrm{IU} / \mathrm{mL}$ ) at 28 days. About $81 \%$ of patients attained HBV DNA levels lower than the lower limit of quantitation [33]. However, no HBsAg change was observed during 4 weeks of treatment and viral rebound was observed after stopping treatment. In another phase 1 clinical trial using a type II CpAM ABI-H0731 in combination with ETV showed that the drug was well tolerated with a decrease in HBV DNA and HBV RNA levels [34]. A recent phase 1 study using a different type II CpAM JNJ-6379 showed that all doses of JNJ-6379 were well tolerated, showed dose-dependent pharmacokinetics, and had potent antiviral activity (decreases in HBV DNA and HBV RNA) in treatment-naive patients with chronic HBV infection [35]. A triple combination of an RNAi (JNJ-3989 $200 \mathrm{mg}$ every 4 weeks for three doses), a CmAM (JNJ-6379 $250 \mathrm{mg}$ daily for 12 weeks) and an NA (daily) in patients with CHB was well tolerated and all patients achieved robust reductions in $\mathrm{HBsAg}$ $\left(>1.0 \log _{10} \mathrm{IU} / \mathrm{mL}\right), \mathrm{HBV}$ DNA, and HBV RNA regardless of HBeAg status [36].

\section{3) HBV attachment/entry inhibitors}

Bulevirtide (Myrcludex) is a first-in-class entry inhibitor that binds to sodium taurocholate cotransporting polypeptide (NTCP) surface receptors that HBV uses to enter hepatocytes. Bulevirtide was recently approved in the European Union (EU) for the treatment of chronic HDV infection in HDV RNA positive adult patients with compensated liver disease. So far, most studies are on chronic hepatitis D infection; however, in a phase 2 randomized clinical study on HBV/HDV co-infection, the combination of Bulevirtide and Peg-IFN achieved a decline of $\mathrm{HBsAg}>1.0 \log _{10} \mathrm{IU} / \mathrm{mL}$ or undetectable HBsAg in $40 \%$ of the patients, in addition to high rate of HDV RNA suppression. An ongoing trial in CHB mono-infection is expected to have results soon (NCT02888106) [37].

\section{4) Inhibition of $\mathrm{HBsAg}$ release}

Nucleic acid polymers (NAPs) inhibit assembly and secretion of HBV subviral particles. As subviral particles account for greater than $99.99 \%$ of HBsAg in the blood, NAPs constitute an effective means of clearing HBsAg from the serum of pa- tients with chronic HBV infection [38]. In an open-label, phase 2 study of the safety and efficacy of the NAPs REP 2139 or REP 2165 combined with TDF and pegylated interferon alpha-2a (Peg-IFN-2a) in HBeAg- CHB patients, the addition of either NAP significantly increased rates of HBsAg loss and HBsAg seroconversion during therapy and functional cure after therapy [39].

\section{5) Neutralization}

Hepabig gene (lenvervimab) is a recombinant hepatitis B immunoglobulin that binds to HBsAg to cause neutralization of circulating virions or surface antigens through formation of immune complexes. It can also inhibit re-entry of the virus by binding to HBsAg. In a prospective, open-label dose escalation phase I trial, single and multiple doses of lenvervimab were administered in four different doses $(80,000 \mathrm{IU}, 120,000$ IU, 180,000 IU or $240,000 \mathrm{IU})$ to $\mathrm{CHB}$ patients, and virological suppression occurred in $\mathrm{HBeAg}$ - $\mathrm{CHB}$ patients with or without NA therapy [40]. Lenvervimab was well-tolerated and reduced levels of HBsAg to below undetectable levels for up to 1 month in patients with $\mathrm{CHB}$ infection. A double-blind, randomized, phase IIa study to evaluate its efficacy and safety in CHB patients on NAs is ongoing.

\section{6) Toll-like receptor (TLR) agonists}

TLRs constitute the first line of defense against invading microorganisms. The activation of TLR-mediated pathways results in suppression of HBV replication and restoration of HBV-specific adaptive immunity. In a double-blind, randomized, placebo-controlled phase II study, chronic HBV patients receiving once-weekly oral vesatolimod (GS-9620, TLR-7 agonist) induced an HBV-specific immune response, but without a significant decline in HBsAg [41]. Another phase 2 clinical study showed that selgantolimod (GS-9688, TLR- 8 agonist) up to $3 \mathrm{mg}$ once weekly for 24 weeks was safe and well tolerated and resulted in modest decline in HBsAg levels from baseline (5\% rate of $\mathrm{HBsAg}$ loss, $16 \%$ of $\mathrm{HBeAg}$ loss) in virally suppressed CHB patients [42]. The HBsAg decline was sustained off-treatment for 24 weeks at week 48. Another phase 2 randomized double-blinded placebo-controlled study on viremic patients with $\mathrm{CHB}$, weekly oral selgantolimod for 24 weeks with TAF followed by TAF for an additional 24 weeks resulted in a decline in HBsAg levels to $>0.3 \log _{10}$ $\mathrm{IU} / \mathrm{mL}$ in the selgantolimod plus TAF group only, although no patients achieved the primary endpoint of HBsAg decline $>1$ $\log _{10} \mathrm{IU} / \mathrm{mL}[43]$.

7) Retinoic acid-inducible gene-1 (RIG-I) agonists

The RIG-I agonist SB9200 (inarigivir), a nucleotide-binding oligomerization domain-containing protein 2 , is an oral HBV antiviral with both direct activity and immune-modulating activity via RIG. In the ACHIEVE study (Study Evaluating the 
Safety, Pharmacokinetics, and Antiviral Efficacy of SB 9200 in Subjects Infected with Chronic HBV), 80 treatment-naive non-cirrhotic $\mathrm{CHB}$ patients received ascending dose inarigivir for 12 weeks followed by a switch to 12 weeks of TDF 300 mg daily. HBV DNA and RNA reductions were achieved in both $\mathrm{HBeAg}+$ and $\mathrm{HBeAg}$ - patients in a dose-dependent manner, with more significant reduction in $\mathrm{HBeAg}$ - patients than $\mathrm{HBeAg}+$ patients, that being greater in the latter. An $\mathrm{HBsAg}$ reduction of $>0.5 \log _{10}$ at either 12 or 24 weeks was seen in $22 \%$ of patients with a mean reduction of $0.8 \log _{10}$ and a maximal reduction of $1.4 \log _{10}$. Unlike HBV DNA, HBsAg decline was not dose-dependent. Further studies at doses of up to 400 mg daily in combination with TDF or added to NA-suppressed patients are under way [44].

\section{8) Therapeutic vaccination}

GS-4774 is a therapeutic vaccine engineered to restore the HBV-specific T-cell immune response to suppress HBV replication and reduce the number of cells containing HBV. In a phase 2 open-label study evaluating the safety and efficacy of GS-4774 in combination of TDF in treatment-naive CHB patients, although it can increase production of interferon (IFN)- $\gamma$, tumor necrosis factor (TNF), and interleukin 2 (IL2) by $\mathrm{CD}^{+} \mathrm{T}$ cells, it failed to reduce levels of HBsAg [45]. However, the strong immune stimulatory effect on $\mathrm{CD} 8^{+} \mathrm{T}$ cells might be used in combination with other antiviral agents to boost the antivirus immune response.

TG1050 is another multi-antigenic adenovirus-based Tcell-inducing vaccine. In a phase 1 clinical trial assessing the safety and efficacy of TG1050 in virally suppressed CHB patients, single or multiple doses of TG1050 were able to induce HBV-specific cellular immune response. Overall, minor decreases of HBsAg were observed while a number of vaccinees reached unquantifiable HBcrAg by end of the study [46].

\section{9) Checkpoint inhibitors}

Programmed cell death protein 1 (PD-1), a checkpoint protein, is highly expressed on HBV-specific T cells and is associated with the dysfunctional T-cell responses in CHB patients. Checkpoint inhibitors direct against PD-1 and restore T-cell dysfunction [47]. Recently, a phase Ib pilot study evaluated anti-PD-1 (nivolumab) treatment with or without GS-4774 (therapeutic vaccine) in virally suppressed $\mathrm{HBeAg}$ - $\mathrm{CHB}$ patients. Patients receiving the higher dose $(0.3 \mathrm{ng} / \mathrm{kg})$ showed a significant HBsAg reduction from baseline, with three patients experiencing declines of $>0.5 \log _{10}$ by the end of study and one patient had loss of HBsAg [48].

Overall, advances have been made in recent years to target a functional cure of CHB. However, monotherapy will unlikely achieve the goal due to complexity of the virus. A better chance of functional cure of HBV infection may come from a combination of new drugs that act via different mechanisms. Currently, the approach is to use a combination of multiple drugs including a backbone of an NA, one or more new direct acting antiviral drugs, and at least one immunomodulator [25]. Further studies are needed to demonstrate the safety and efficacy of these combinations. In addition, more precision lab tests (such as HBV DNA and measurement of HBcrAg) are being developed and validated to differentiate disease states and/ or define stopping rules to accommodate the rapid advances in CHB treatments.

\section{HCV}

$\mathrm{HCV}$ is an enveloped RNA virus from the Flaviviridae family and genus hepacivirus. Currently, there are seven recognized HCV genotypes based on structural diversity of the viral genome (30-35\% nucleotide variability). This classification is further divided into 67 sub-genotypes $(<15 \%$ nucleotide variability) [49]. Some of these genotypes have different geographic distributions; however, genotypes 1 and 3 have the highest incidence worldwide [50]. A combination of polymerase chain reaction (PCR) and phylogenetic analysis is often implemented to determine the HCV genotype of each patient. Different $\mathrm{HCV}$ genotypes have shown variable responses to different treatment regimens; therefore, genotype analysis has routinely been used as a strategy to guide focused treatment.

\section{Diagnosis}

Diagnostic accuracy of HCV testing has improved with the development of the third-generation HCV EIA. This test is nearly $99 \%$ sensitive and specific for determining whether a patient has ever been infected with HCV, but it does not differentiate between acute versus chronic infections [51]. Patients who have a positive HCV EIA undergo quantitative HCV RNA testing using nucleic acid amplification technology (NAAT) to diagnose active infection [52]. In instances where HCV RNA testing is unavailable, detection and quantification of $\mathrm{HCV}$ core antigen can be used in aiding diagnosis [53]. Furthermore, the development of POC tests that serve as anti-HCV rapid diagnostic tests have been used as effective alternatives to the traditional method HCV testing, with some tests having sensitivity as high as $99 \%$ [54]. These POC tests are implemented in areas with health care structures that cannot support the more complex EIA and NAAT testing.

\section{Treatment}

\section{Historic treatment option}

Early/previous treatment options for HCV revolved around immunomodulatory agents including IFN and pegylated IFN therapy to induce a sustained viral response (SVR). SVR refers to achieving an undetectable HCV viral load at least 12 - 24 weeks following treatment cessation [55]. Ribavarin, a guanosine nucleoside analogue, was also introduced to be used alongside IFN therapy for HCV treatment [56]. Although these therapies provided initial treatment, they had several side ef- 
Table 3. Class I Evidence (Beneficial, Effective, and Useful Treatment) With Data From Multiple Randomized Clinical Trials, MetaAnalysis or Equivalent

\begin{tabular}{ll}
\hline Patient population & First line treatment regimens \\
\hline Genotype 1a without cirrhosis & Elbasvir/grazoprevir, glecaprevir/pibrentasvir, ledipasvir/sofosbuvir, sofosbuvir/velpatasvir \\
Genotype 1a + compensated cirrhosis & Elbasvir/grazoprevir, ledipasvir/sofosbuvir, sofosbuvir/velpatasvir, glecaprevir /pibrentasvir \\
Genotype 1b without cirrhosis & Elbasvir/grazoprevir, glecaprevir/pibrentasvir, ledipasvir/sofosbuvir, sofosbuvir/velpatasvir \\
Genotype 1b + compensated cirrhosis & Elbasvir/grazoprevir, ledipasvir/sofosbuvir, sofosbuvir/velpatasvir \\
Genotype 2 without cirrhosis & Glecaprevir/pibrentasvir, sofosbuvir/velpatasvir \\
Genotype 2+ compensated cirrhosis & Sofosbuvir/velpatasvir \\
Genotype 3 without cirrhosis & Glecaprevir/pibrentasvir, sofosbuvir/velpatasvir \\
Genotype 3+ compensated cirrhosis & Sofosbuvir/velpatasvir \\
Genotype 4 without cirrhosis & Elbasvir/grazoprevir, glecaprevir/pibrentasvir, ledipasvir/sofosbuvir, sofosbuvir/velpatasvir \\
Genotype $4+$ compensated cirrhosis & Sofosbuvir/velpatasvir \\
Genotypes $5+6^{\text {b }}$ & Glecaprevir/pibrentasvir \\
\hline
\end{tabular}

apatients without baseline NS5A RAS Y93H for velpatasvir. ${ }^{b}$ Patients both with and without cirrhosis.

fects and only maintained an SVR in $40-50 \%$ of patients [57].

\section{Direct antiviral agents (DAAs)}

Treatment of HCV has expanded over time with the development of medical therapy to achieve SVR. With the development of DAAs, treatment of HCV has evolved to targeting specific components that dictate HCV processing and replication [50]. Specific DAA treatment regimens that have been approved as first-line therapy for each HCV genotype are included in Table 3 [58].

\section{1) $\mathrm{NS} 3 / 4 \mathrm{~A}$ protease inhibitors}

The HCV multifunctional protein complex known as NS3/4A is responsible for cleaving precursor proteins into the nonstructural protein products NS3, NS4A, NS4B, NS5A, and NS5B [59]. This protease complex is essential for viral replication and serves as a target for medical therapy. Boceprevir and telaprevir were developed first and are classified as first-generation inhibitors of NS3/4A protease. These medications are no longer used in clinical practice. Simeprevir, paritaprevir, grazoprevir, glecaprevir and voxilaprevir are second-generation protease inhibitors that are currently used in clinical practice [60]. These medications are often combined with other drugs with different mechanisms of action including pegylated IFN and ribavirin. Selection of these specific drug regimens is tailored to various $\mathrm{HCV}$ genotypes while taking into account of patient's co-morbidities $[50,61]$.

\section{2) NS5A inhibitors}

NS5A is a nonstructural protein that is involved in the process of HCV replication. Ledipasvir, ombitasvir, daclatasvir, elbasvir, velpatasvir and pibrentasvir were developed as medications that inhibit hyperphophorylation of NS5A, thereby halting key steps in viral replication [62]. These drugs are also used in combination with other HCV medications and have proven to be effective towards achieving SVR in several patient populations.

\section{3) NS5B inhibitors}

Nucleotide and non-nucleoside NS5B inhibitors act upon the catalytic site of action of NS5B, an RNA-dependent RNA polymerase that replicates the HCV genome [63]. Sofosbuvir was developed as a nucleotide analog that acts directly on the active side of NS5B polymerase and gets incorporated into the RNA chain to induce chain termination. Dasabuvir is a nonnucleoside inhibitor of NS5B that gets activated by a cellular kinase and targets an allosteric site to halt viral replication [63].

\section{HCV screening and treatment in specific patient populations}

\section{1) IV drug users}

People who inject drugs (PWID) remain a high-risk group for HCV infection with a global estimate of over $50-60 \%$ of this population being HCV positive $[64,65]$. The sharing of injection drug use equipment is one of the primary modes of viral transmission amongst this group. PWID are the population also most at risk for $\mathrm{HCV}$ infection [64]. A large proportion of people in prisons or other closed detention centers consist of PWID. The criminalization of injection drug use has made these custodial settings highly prevalent in HCV with high risk for further HCV transmission [66].

In response to the increased prevalence of $\mathrm{HCV}$ in PWID, the $\mathrm{WHO}$ has recommended yearly screening for $\mathrm{HCV}$ in this group [67]. Despite these recommendations, there have been lower rates of HCV testing and treatment among PWID. This has been thought to be secondary to decreased level of risk 
awareness, difficulty finding access or availability of HCV testing, social stigma, as well as potential discrimination on behalf of healthcare providers [68].

\section{2) $\mathrm{HCV} / \mathrm{HIV}$ co-infection}

There are about 37 million people infected with HIV globally with around $20-30 \%$ of them also being co-infected with HCV [69]. HCV/HIV co-infected individuals are at increased risk of liver-related mortality with these patients typically having a higher viral load and a higher chance of developing chronic infection associated with the rapid development of advanced liver disease $[70,71]$. Treatment of HCV/HIV co-infection remains a challenge because of the side-effects and drug-drug interactions between HCV DAA and HIV anti-retroviral therapy. Typically, interruption of anti-retroviral therapy is not recommended prior to initiation of HCV DAA therapy [70]. Treatment of these patients oftentimes requires collaboration with an HIV or infectious disease practitioner.

3) HCV in chronic kidney disease (CKD)/end-stage renal disease (ESRD)

HCV has been shown to be associated with syndromes of glomerulonephritis as well as the development of CKD. Patients with CKD who develop HCV have a higher mortality rate and have a higher likelihood of developing ESRD. This is seen with a higher incidence of dialysis patients being positive for HCV. Treatment of HCV in ESRD and CKD patients is increasingly important to prevent further complications and improve longterm survivability [72-74]. Most DAAs are metabolized through the liver with only minor renal clearance and routinely do not require an adjustment in dose for $\mathrm{CKD} / \mathrm{ESRD}$ patients. In this patient population, both duration as well as composition of treatment regimens vary based on HCV genotypes as well as glomerular filtration rate (GFR) with elbasvir/grazoprevir, glecaprevir/ pibrentasvir, and sofosbuvir regimens being among some of the medications deemed safe and tolerable in patients with GFR < 30 (CKD4, CKD5, or hemodialysis patients) [75].

\section{4) $\mathrm{HCC}$ risk in patients with chronic $\mathrm{HCV}$ following treat- ment}

As HCV leads to hepatic fibrosis and cirrhosis, HCV infection remains a major risk factor for the development of HCC. Although DAAs have been used to induce SVR in HCV infection, patients remain at risk for $\mathrm{HCC}$ following treatment. It has been shown that the absolute risk of HCC development following $\mathrm{HCV}$ treatment can be as high as 3.5\% within 12 months of completing treatment [76-78]. Additionally, certain genotypes have been shown to be associated with an increased incidence of HCC including genotypes 3 and 6. Other risk factors for increased HCC incidence in these patients include co-infection with either HIV or HBV, smoking and alcohol use, as well as diabetes and obesity [79]. Given that patients with chronic HCV remain at increased risk of HCC, HCC surveillance remains important in these patients with advanced fibrotic or cirrhotic liver morphology even after treatment with DAAs therapy [78].

\section{HCV treatment failure}

With the various HCV genotypes in addition to the underlying error prone replication pattern of $\mathrm{HCV}$, treatment failure can be encountered. Clinical trials have shown that DAA treatment failure or relapse occurs in $<10 \%$ of cases. One study with 3,830 patients with either cirrhosis or advanced fibrosis showed that 139 (3.6\%) of patients failed to achieve SVR following DAA therapy [80]. Viral variants with polymorphisms referred to as resistant-associated substitutions (RASs) have been shown to induce HCV treatment failure. RASs occur in a minority of patients, and sub-therapeutic DAA levels can make one more prone to developing RASs. RASs in HCV proteins NS5A and NS3 have been seen in the setting of previous exposure to NS5A and NS3 DAAs. Such drug resistance impedes one's ability to mount an SVR [81]. In instances where DAAs containing NS5A inhibitors fail, the AASLD and IDSA recommend testing for NS5A RASs [73]. Furthermore, RASs testing has also been proposed in various HCV genotypes (genotype $1 \mathrm{a}$ and 3) prior to initiation of DAA treatment [60,81].

In addition to primary drug resistance due to RASs, treatment failure has also been associated with medication side-effects, drug-drug interactions, and other co-morbidities. DAAs and other antiviral treatment regimens have been shown to be associated with lactic acidosis in addition to hepatic decompensation that has led to mortality and overall treatment failure [82]. Other reported complications hindering achievement of SVR include severe pulmonary toxicity and pulmonary hypertension [83]. Patients with HIV as well as active illicit drug use, mental illness and advanced liver fibrosis are more prone to treatment failure and require more targeted and enhanced DAA treatment regimens to ensure SVR achievement [84].

\section{HCV liver transplant complications}

\section{Recurrence of $\mathrm{HCV}$ in liver allografts}

Patients with a history HCV with an active pre-transplant viremia commonly develop HCV recurrence following liver transplant. Infection of the donated allograft occurs upon reperfusion and requires histological evidence for diagnosis [85, 86]. The clinical presentation of HCV recurrence varies from chronic infection to fibrosing cholestatic hepatitis [87]. Fibrosing cholestatic hepatitis refers to a severe pattern of recurrent disease associated with extremely high levels of HCV RNA that leads to graft loss within a few weeks of onset and typically occurs in $<10 \%$ of cases $[87,88]$.

The course of chronic $\mathrm{HCV}$ is typically more aggressive in immunocompromised patients than in immunocompetent patients [89]. Almost one-third of chronically infected patients develop allograft cirrhosis within 5 - 7 years following transplant [90]. Antiviral therapy has been used to modify the 
course of recurrent HCV-graft disease to achieve SVR with the underlying goal to achieve histological and necro-inflammatory allograft recovery $[87,91]$. Medical treatment remains a challenge as DAA in addition to other antiviral therapies (interferon and ribavarin) has drug-drug interactions with immunosuppressant agents used in transplant patients [60]. Despite these challenges, overall graft survival among HCV-positive recipients has increased substantially since the introduction of DAA therapy [92]. In patients with histopathological evidence of established graft cirrhosis, the only treatment option is retransplant which accounts for only $10 \%$ of all liver transplants and has overall worse outcomes than primary transplants. Although the high cost, historically poor outcomes, and limited availability of hepatic transplants have made re-transplant a contested topic, the application of DAAs during re-transplant has led to overall improved patient and graft survival rates, similar to those of non-HCV re-transplant recipients [93].

The timing of HCV treatment in association with liver transplant is an important consideration due to the variable outcomes for specific populations. Patients with chronic HCV with a MELD score $<16$ typically undergo DAA therapy to achieve SVR prior to liver transplant given the mortality benefit as well as possible transplant delisting secondary to clinical improvement [94]. Those with MELD scores between 16 and 20 require individualized treatment regimens regarding when to initiate DAA given the potential to precipitate liver failure or other complications with antiviral therapy. DAA therapy in those with MELD > 20 has been shown to have optimal benefit when initiated following liver transplantation at the earliest point of clinical stability ( 2 - 4 weeks post-transplant) [94, 95].

\section{Use of HCV seropositive organs for transplantation}

Given the growing need for liver transplants across the globe, $\mathrm{HCV}$ seropositive viremic and non-viremic individuals have been used as organ donors for patients requiring liver transplant. Data have shown that HCV seronegative, non-viremic recipients showed promising outcomes and maintained SVR with DAA-based treatment regimens following transplant [92, 96, 97]. As HCV mortality continues to rise globally, DAAs have been shown to increase post-transplant survival and remain effect tools to guide liver transplant planning and treatment [98].

\section{HCV global elimination}

According to the WHO, there is a global estimate of 71 million chronic HCV cases with a growing mortality of over 400,000 deaths annually. Most of these deaths are related to the developed cirrhosis as well as HCC $[3,99]$. Various HCV genotypes are more prevalent in different geographic territories with the highest prevalence of infection being spread across areas of central and eastern Asia as well as north and West Africa [2]. High risk groups include injection drug users, people with high-risk sexual practices (multiple sexual partners, men who have sex with men), healthcare workers who suffer needle-stick accidents, patients who have undergone certain procedures such as hemodialysis in facilities with inadequate infectious control, as well as those who have had blood transfusions or organ donations prior to $1992[69,70]$.

In contrast to other infectious diseases such as tuberculosis (TB), HIV, and malaria that have seen a steady decline in prevalence and mortality over the past decade, HCV infection remains on the rise and is a significant global health problem moving forward [100]. Despite its high prevalence, it is estimated that only $20 \%$ of infected individual have been diagnosed and only $7 \%$ have received treatment worldwide [2, 3$]$. $\mathrm{HCV}$ remains the leading cause of $\mathrm{HCC}$ in the United States and is one of the most common causes of HCC worldwide [78].

With the development of DAAs, the WHO developed the Global Health Sector Strategy for Viral Hepatitis in order to target the spread of HCV with the goal of potentially eliminating HCV as a major global threat by 2030. Most HCV carriers remain undiagnosed until they begin to develop symptoms of cirrhosis or are found to abnormal liver function tests [101]. Endeavors towards $\mathrm{HCV}$ elimination have placed emphasis on wider and more prevalent testing in order to diagnose patients unaware of their $\mathrm{HCV}$ status. The goal of more widespread testing in high-risk populations serves to prevent further transmission, thereby leading to overall incidence reduction. The WHO has also proposed focused testing in populations with increased $\mathrm{HCV}$ risk and prevalence (anti-HCV antibodies in $>2-5 \%$ of the general population) as well as groups with sign and symptoms consistent with potential $\mathrm{HCV}$ infection. Undiagnosed patients may miss the benefits of HCV therapy: a potential $65 \%$ reduction in liver-related death [2, $3,101]$. Countries across the globe such Portugal, Egypt, Netherlands, France, and the United States have specific implemented guidelines to direct HCV testing per the demographic and geographic distribution of their high-risk populations [1, 102].

Despite expanding HCV testing globally, achieving the WHO's goal of HCV elimination by 2030 remains a challenge with several obstacles hindering global elimination. The diagnostic algorithm being a traditional two-test process provides limitations to those lost to follow-up [103]. These patients may ultimately suffer HCV-related mortality. Transitioning to a one-step method of diagnosis may provide more comprehensive treatment. In addition, several nations with high $\mathrm{HCV}$ prevalence lack financial, laboratory, or medical resources to comply with the WHO's targets [104]. At the individual level, certain at-risk groups do not have the financial capacity or community access to seek HCV care [105]. Furthermore, the social stigma towards HCV and lack of public awareness towards the global threat of HCV impede further upscaling of HCV diagnosis and treatment [103] (Table 4).

\section{HDV}

HDV is a single-stranded RNA virus of the genus Deltavirus. It uses the HBsAg as a viral envelope and shares the same hepatocyte receptor for viral entry [106]. Eight HDV genotypes have been identified. Two forms of infection exist including co-infection with HBV that can be self-limiting and superinfection in a patient with known HBV infection, which usually leads to chronicity in most cases. Among HBsAg+ people, 
Table 4. Summary of the Diagnostic and Therpaeutic Strategies for Hepatitis Viruses

\begin{tabular}{lll}
\hline Virus & Diagnostic testing modalities & Treatment strategies \\
\hline HAV & $\begin{array}{l}\text { IgM anti-HAV antibodies via EIA } \\
\text { Rapid immunochromatographic test }\end{array}$ & Supportive care \\
& IgG anti-HAV rapid salivary test & \\
HBV & HBsAg, HBeAg, and IgM/IgG anti-HBc antibodies via EIA & Interferon formulations \\
& Quantitative HBV DNA level via NAAT & Nucles(t)ide analogs \\
& Quantitative HBsAg & \\
& HBcrAg & \\
POC HBsAg & IgG anti-HCV antibodies via EIA & \\
& Quantitative HCV RNA level via NAAT & DAAT \\
& POC anti-HCV & Interferon formulations \\
HDV & Total anti-HDV antibody & No FDA approved formulations \\
& Quantitative HDV RNA level via NAAT & Bulevirtide (myrcludex): viral entry inhibitor approved in Europe \\
HEV & $\begin{array}{l}\text { Anti-HEV IgG/IgM antibodies via EIA } \\
\text { Quantitative HEV RNA via NAAT }\end{array}$ & $\begin{array}{l}\text { Ribavirin } \pm \text { pegylated interferon } \\
\text { HEV vaccine in China }\end{array}$ \\
& POC anti-HEV1 and anti-HEV3 IgM & \\
\hline
\end{tabular}

HAV: hepatitis A virus; HBV: hepatitis B virus; HCV: hepatitis C virus; HDV: hepatitis D virus; HEV: hepatitis E virus; EIA: enzyme immunoassay; IgM: immunoglobulin M; HBsAg: HBV surface antigen; HBeAg: hepatitis B E antigen; HBcrAg: Hepatitis B core-related antigen; NAAT: nucleic acid amplification technology; POC: point of care.

estimated HDV prevalence is $4.5 \%$ (95\% confidence interval (CI) 3.6 - 5.7). HDV prevalence is higher in people who inject drugs and who have HCV or HIV. It causes an estimated $18 \%$ of cirrhosis and $20 \%$ of HCC associated with HBV [106].

\section{Diagnosis}

AASLD recommended testing $\mathrm{HBsAg}+$ persons at risk for $\mathrm{HDV}$, including those with HIV infection, persons who inject drugs, men who have sex with men and immigrants from areas of high HDV endemicity [107]. For patients with CHB infection with elevated liver enzymes but undetectable HBV DNA, testing HDV infection is also recommended [107]. While EASL and APASL recommend screening all patients with $\mathrm{CHB}$. Patients should be tested for total anti-HDV antibody with follow-up HDV RNA testing to confirm active hepatitis D infection if total anti-HDV antibody is positive. Despite the recommendations, HDV screening is low in the United States. One Veterans Administration (VA) study in 2017 showed that only $8.5 \%$ of HBsAg+ patients ever underwent anti-HDV antibody screening [108].

\section{Treatments}

\section{Viral entry inhibitors}

There are no currently Food and Drug Administration (FDA)approved therapies in the United States. However, in Europe, a viral entry inhibitor bulevirtide (myrcludex) was recently approved in July 2020 as the first drug for the treatment of chronic HDV infection in HDV RNA positive adult patients with compensated liver disease [109]. The approved dose is $2 \mathrm{mg}$ self-ad- ministered as a once-daily injection with or without NAs such as TDF. Bulevirtide is an entry inhibitor that binds to NTCP surface receptors that are shared by $\mathrm{HBV}$ and $\mathrm{HCV}$. Two randomized controlled studies using bulevirtide in combination with either Peg-IFN or TDF. In the phase II MYR202 (NCT03546621) trial in patients with chronic hepatitis D with liver cirrhosis, or who failed previous IFN therapy, or for whom such therapy was contraindicated (including history of IFN intolerance), treatment with bulevirtide $2 \mathrm{mg}$ plus tenofovir was associated with a significantly increased proportion of patients achieving undetectable HDV RNA or decrease by $\geq 2 \log _{10}$ from baseline to week 24 than tenofovir alone $(53.6 \%$ vs. $3.6 \%$ of patients, respectively) [110]. However, HDV RNA relapse was reported in $60 \%$ of HDV RNA responders in the bulevirtide $2 \mathrm{mg}$ plus tenofovir arm at 12 weeks' treatment-free follow-up, indicating a longterm use of bulevirtide is needed for sustained suppression of hepatitis D. In the phase II MYR 203 (NCT02888106) study, serum HDV RNA was undetectable in more bulevirtide $2 \mathrm{mg}$ plus Peg-INF- $\alpha$-2a recipients than bulevirtide or Peg-INF- $\alpha-2 \mathrm{a}$ recipients ( $80 \%$ vs. $13.3 \%$ vs. $13.3 \%$ of patients, respectively) at 48 weeks and the effects maintained for up to 72 weeks (24 weeks' treatment-free follow-up). Interestingly, HBsAg levels declined (by $>1 \log$ ) or were undetectable in $46.7 \%$ of bulevirtide $2 \mathrm{mg}$ plus Peg-INF- $\alpha$-2a recipients. No changes were seen in monotherapy recipients [37].

\section{IFN and antiviral agents}

The Hep-Net/International Delta Hepatitis Intervention Trial (HIDIT-1) studied combination of Peg-IFN and adefovir in chronic hepatitis D patients. Peg-INF with or without adefovir groups achieved a $2.5 \mathrm{log}$ decline in median HDV RNA at 48 weeks of treatment, while no changes was noted in adefovir 
group [111]. In a follow-up HIDIT-2 study when adefovir was replaced by tenofovir and the treatment was extended to 96 weeks, no difference was noted between Peg-IFN with tenofovir group or Peg-IFN alone group [112]. This indicated that the combination of NAs with IFN does not seem to provide additional benefit in chronic HDV infection.

\section{The prenylation inhibitor}

The prenylation inhibitor, lonafarnib (LNF) can prevent proper interaction of large HDAg (L-HDAg) with HBsAg in HDV. In the four series of LOWR HDV (LOnafarnib With and without Ritonavir in HDV) studies, combinations of low dose LNF (oral 25 or $50 \mathrm{mg}$ twice daily) with low dose ritonovir (oral $100 \mathrm{mg}$ twice daily) with Peg-IFN- $\alpha$-2a resulted in 88.9\% (8/9) decline of HDV RNA to undetectable or a greater than or equal to 2 $\log _{10}$ IU/L decline in serum HDV RNA by week 24 [113]. A phase 3 study for HDV (Delta Liver Improvement and Virologic Response, D-LIVR) (NCT03719313), studying LNF with RTV with or without Peg-IFN- $\alpha-2 \mathrm{a}$ in 400 subjects is ongoing.

\section{IFN lambda-1a}

Peg-IFN-lambda-1a is a type-III IFN that has demonstrated antiviral activity against $\mathrm{HBV}$ and $\mathrm{HCV}$, but also showed antiviral activity against HDV in a recent clinical study. In this study, Peg-IFN lambda monotherapy (120 or $180 \mathrm{mg}$ weekly) for 48 weeks showed that both doses have antiviral activity against HDV. When giving high dose, 64\% patients achieved either a $2 \log _{10}$ decline in HDV RNA or undetectable at the end of therapy, which was sustained in seven out of $14(50 \%)$ subjects 24 weeks after therapy [114]. Currently, an open-label clinical trial exploring lambda IFN in combination with LNF and ritonavir (RTV) for 24 weeks is ongoing (NCT03600714).

\section{Nucleic acid polymers (NAPs)}

NAPs are another type of therapy that is being studied. NAPs are phosphorothioated oligonucleotides that can suppress HBV replication. It is presumed that they can also inhibit the HDV replication cycle. In a phase 2, proof-of-concept study (NCT02233075) studying patients with compensated hepatitis D, the NAP REP 2139-Ca was given as an intravenous infusion once weekly, with add-on Peg-IFN starting at week 15 for another 15 weeks. REP 2139-Ca demonstrated antiviral effects against both HBV and HDV. About 75\% (9/ 12) subjects became HDV RNA negative in serum with a mean HDV RNA decline of $5.34 \log _{10}$ IU/L [115]. A follow-up study (NCT02876419) exploring the durability of these responses through 3 years of follow-up is currently ongoing.

\section{HEV}

HEV is a single-stranded, non-enveloped, RNA icosahedral virus. There are eight genotypes currently identified, with the HEV1, HEV2, HEV3, and HEV4 genotypes being the most frequently seen in humans. HEV1 and HEV2 contaminate water supplies and are associated with severe hepatitis in pregnant women and children in developing countries [116]. HEV3 and HEV4 are zoonotic, but infection in humans can occur with fecal contamination of water or undercooked meat. There are estimated 20 million HEV1 and HEV2 infections annually, with 3.3 million symptomatic cases, leading to over 60,000 deaths [116].

Diagnosis of HEV is usually carried out with direct testing via PCR of HEV RNA or with indirect testing via detection of anti-HEV IgM or IgG through EIA. Increasingly, POC testing is showing promise as tool for early detection. In 2016, an Italian study found the sensitivity of two rapid tests for anti-HEV1 and anti-HEV3 IgM to be $96 \%$ and $93 \%$, and the specificity for both to be $100 \%$ [117]. A 2017 study tested a saliva-based EIA against commercial plasma and serum-based kits and found similar sensitivity and specificities [118].

While the majority of HEV infection cases are asymptomatic, 5-30\% progress to acute hepatitis [119]. Particular attention should be paid to affected pregnant women and the immunocompromised, as they are at higher risk for developing complications including fulminant and chronic hepatitis.

\section{Manifestations and treatment in pregnant women}

HEV1 and HEV2 are well-documented causes of fulminant hepatitis in pregnant women, particularly those in the third trimester. The HEV1 genotype poses the highest risk, with a systematic review showing median maternal fetal, and neonatal case-fatality rates of $26 \%, 33 \%$, and $8 \%$, respectively [120]. One proposed mechanism for the higher virulence of HEV1 in pregnant women may be attributed to HEV1's greater affinity towards stromal cells, the decidua basalis, and the fetal placenta. An ex vivo model in 2018 demonstrated that proliferation of HEV1 along the maternal-fetal barrier led to release of pro-inflammatory cytokines, cellular death, and necrosis [121]. Hormonal changes during pregnancy may also play a role, as pregnant women who developed fulminant hepatitis had higher serum levels of estrogen, progesterone, and betahuman chorionic gonadotropin ( $\beta$-hCG) [122].

Currently, the standard of care for acute HEV is ribavirin with or without Peg-IFN, although there are no clear guidelines on the dosage and duration of treatment. As both are contraindicated in pregnancy due to teratogenicity, focus should be on prevention. In those who are appropriate candidates, liver transplant should be considered early in the course of disease [123].

\section{Treatment in the immunocompromised hepatitis $\mathbf{E}$ patients}

In the immunocompromised, acute HEV infection may lead to chronic hepatitis and cirrhosis. Confirmation of infection usually is performed via direct testing via PCR of HEV RNA, as IgM and IgG may both be negative in the setting of immu- 
nosuppression [124].

In solid organ-transplant recipients, the first step in treatment is a dose reduction in immunosuppressive medications, with studies showing a nearly $33 \%$ rate of complete remission by this method alone [125]. In other patients or in those without adequate response to a reduction in immunosuppression, ribavirin has been shown to be effective. In one study, $78 \%$ of patients achieved sustained virologic clearance after a median of 3 months of treatment at $600 \mathrm{mg} /$ day [126].

In patients with ribavirin-resistant infections, pegylated IFN-alpha has also been shown in a few small studies to be efficacious, although its contraindication in non-liver transplant patients due to risk of organ rejection, as well as the limited amount of data on its efficacy, limits its use [127, 128]. Several studies have demonstrated that while sofosbuvir has antiviral activity against $\mathrm{HEV}$, treatment does not lead to sustained virologic response [129-131]. Other agents including 2'-Cmethylguanosine, silvestrol, and compounds GPC-N114 and NITD00840 have shown promise in in vitro studies [131, 132]. However, further investigation and clinical trials are required before they can be considered for use in humans.

\section{HEV vaccine}

In 2011, a recombinant hepatitis E vaccine (HEV 239, Hecolin) was approved for use in those aged 16 - 65 years in China after a phase 3 trial involving over 110,000 participants and showed over 99\% efficacy against the HEV1 and HEV4 genotypes with few adverse events [133]. While the vaccine has not yet gained approval in other countries, in 2020, the Norwegian Institute of Public Health completed recruitment for a phase IV study investigating the efficacy of the vaccine in pregnant women in Bangladesh (NCT02759991) [134]. A recent clinical trial in China also demonstrated the safety of the vaccine in those over 65 years old [135]. A National Institute of Allergy and Infectious Diseases (NIAID)-sponsored phase I study in the United States is ongoing (NCT03827395).

\section{HGV}

Hepatitis $\mathrm{G}$ virus (HGV) is a newly discovered and uncommonly reported virus. HGV has a dsRNA structure and is a member of the Flaviviridae family, with an overall design and epidemiological spread similar to that of HCV [136]. The clinical significance of this virus in relationship to hepatic disease and other manifestations remains unclear. There have been no reported definitive downstream impacts of this virus to date [137]; however, case reports and studies have proposed potential associations of this virus with clinic symptoms or other infections. Bhattarai et al reported that HGV may impact or even interfere with HIV replication mechanisms [138]. Co-infection of $\mathrm{HGV}$ with $\mathrm{HBV}, \mathrm{HCV}$, and HDV has been more frequently detected than mono-infection alone. Additionally, despite the majority of HGV-positive cases being clinically asymptomatic, a minority of HGV-positive patients can present with hepatic disease [136]. $\mathrm{HGV}$ has also been reported in cerebrospinal fluid (CSF) analy- sis in the setting of HIV infection [139]. Although our knowledge on this virus remains limited, there are concerns that HGV may alter clinical course in various patient populations. Furthermore, there is concern that medical systems are not appropriately screening for this virus in populations at risk. Wang et al demonstrated through meta-analysis that pooled prevalence of $\mathrm{HGV}$ in donor blood is between $3 \%$ and $4 \%$ in China [140]. This percentage is higher than any other hepatitis virus, and certain groups have proposed increased screening for this virus. Clinical significance of HGV remains unclear and further research is needed to better understand the impact of this virus both as a single agent as well as a co-infection with other viruses.

\section{Conclusion}

Viral hepatitis endemics and pandemics take a heavy toll on lives, communities and health systems. Viral hepatitis is also a growing cause of mortality among people living with HIV. The five hepatitis viruses (A, B, C, D and E) are very different, with different modes of transmission, affecting different populations and resulting in different health outcomes. An effective response requires a range of common actions for prevention, diagnosis, treatment, surveillance, and screening, while at the same time delivering tailored interventions for each of the viruses. Acute hepatitis A infection requires prompt diagnosis and treatment is often supportive. Acute hepatitis B and $\mathrm{C}$ usually is undiagnosed until it becomes chronic. Acute hepatitis $\mathrm{E}$ is more unique in pregnant patients and can cause significant mortality in this population. Worldwide, most of hepatitis-associated morbidity (96\%) and mortality (91\%) is caused by HBV and HCV infections, because these two viruses cause chronic, life-long infections, resulting in irreversible liver damage that leads to cirrhosis and in some cases, $\mathrm{HCC}$. Hepatitis $\mathrm{C}$ treatment is the biggest advancement of viral hepatitis in the past decades, although minor issue is still present. In contrast, despite the recent advances in understanding HBV, significant obstacles exist due to its integration to the host DNA. The first approved medication in EU for hepatitis $\mathrm{D}$ is promising. In the next decade, scientific advances in $\mathrm{HBV}$ virology and immunology are essential to achieve functional cure for patients with CHB. Overall, for the hepatitis elimination targets to be reached by 2030 , substantially more resources and additional innovations are needed to make these interventions widely available. Region-specific strategies are needed that reflect regional epidemiology and disease burden and are supported by a national elimination plan and provision of sufficient resources for implementation.

\section{Acknowledgments}

None to declare.

\section{Financial Disclosure}

None of the authors have relevant disclosures, and this research 
did not receive any specific grant from funding agencies in the public, commercial, or not-for-profit sectors.

\section{Conflict of Interest}

None of the authors have relevant conflict of interest or competing interest to declare related to this review.

\section{Author Contributions}

All authors were involved in idea conception, in-depth literature review, manuscript writing, approval of the final manuscript, and take full responsibility for the manuscript.

\section{Data Availability}

All authors agree to allow this data to be open to the public of accessing.

\section{Abbreviations}

AASLD: American Association for the Study of Liver Diseases; ALT: alanine aminotransferase; Anti-HBc: hepatitis B core antibody; APASL: Asian Pacific Association for the Study of the Liver; cccDNA: covalently closed circular DNA; CHB: chronic hepatitis B; CKD: chronic kidney disease; CpAM: core protein allosteric modulators; CSF: cerebrospinal fluid; D-LIVR: Delta Liver Improvement and Virologic Response; DAA: direct anti-viral agents; EASL: European Association for the Study of the Liver; EIA: enzyme immunoassay; ESRD: end-stage renal disease; ETV: entecavir; EU: European Union; GFR: glomerular filtration rate; HAPs: Heteroaryldihydropyrimidines; HAV: hepatitis A virus; HBcrAg: hepatitis B core-related antigen; HBeAg: hepatitis B E antigen; HBsAg: HBV surface antigen; HBV: hepatitis B virus; HCC: hepatocellular carcinoma; HCV: hepatitis $\mathrm{C}$ virus; HDV: hepatitis D virus; HEV: hepatitis E virus; HIDIT-1: Hep-Net/International Delta Hepatitis Intervention Trial; HIV: human immunodeficiency virus; IgM: immunoglobulin M; IL2: interleukin 2; L-HDAg: large HDAg; LNF: lonafarnib; LOWR HDV: LOnafarnib With and without Ritonavir in HDV; NA: nucleos(t)ide analog; NAAT: nucleic acid amplification technology; NAPs: nucleic acid polymers; NAPs: nucleic acid polymers; NIAID: National Institute of Allergy and Infectious Diseases; NTCP: sodium taurocholate cotransporting polypeptide; p22 Cr: 22 $\mathrm{kDa}$ precore protein; PCR: polymerase chain reaction; PD-1: programmed cell death protein 1; Peg-IFN-2a: pegylated interferon alpha-2a; Peg-IFN-a: pegylated interferon alpha; POC: point of care; PPAs: phenylpropenamides; PWID: people who inject drugs; RASs: resistant-associated substitutions; RDTs: rapid diagnostic tests; RIG-I: retinoic acid-inducible gene-1; RNAi: RNA interference; RTV: ritonavir; siRNA: small interfering RNA; SVR: sustained viral response; TAF: tenofovir alafenamide; TAT: turn-around time; TB: tuberculosis; TDF: tenofovir disoproxil fumarate; TFV: tenofovir; TLRs: Toll-like receptors; TNF: tumor necrosis factor; ULN: upper limit normal; VA: Veterans Administration; WHO: World Health Organization

\section{References}

1. Cox AL, El-Sayed MH, Kao JH, Lazarus JV, Lemoine M, Lok AS, Zoulim F. Progress towards elimination goals for viral hepatitis. Nat Rev Gastroenterol Hepatol. 2020;17(9):533-542.

2. World-Health-Organization. Combating Hepatitis B and C to reach elimination by 2030. 2016.

3. World-Health-Organization. Global hepatitis report 2017. 2017.

4. World-Health-Organization. The global prevalence of hepatitis A virus infection and susceptibility: a systematic review. 2008.

5. Nelson NP, Murphy TV. Hepatitis A: The changing epidemiology of hepatitis A. Clin Liver Dis (Hoboken). 2013;2(6):227-230.

6. Brouwer AF, Zelner JL, Eisenberg MC, Kimmins L, Ladisky M, Collins J, Eisenberg JNS. The impact of vaccination efforts on the spatiotemporal patterns of the hepatitis A outbreak in Michigan, 2016-2018. Epidemiology. 2020;31(5):628-635.

7. de Almeida Ribeiro CR, Amado LA, Tourinho RS, Pinto Lima LR, Melgaco JG, de Almeida AJ, Bastos LS, et al. Accuracy of rapid test for diagnosis of hepatitis A with different infection rate settings and with predictive modeling. Future Microbiol. 2019;14:247-258.

8. Augustine SAJ, Eason TN, Simmons KJ, Griffin SM, Curioso CL, Ramudit MKD, Sams EA, et al. Rapid salivary IgG antibody screening for hepatitis A. J Clin Microbiol. 2020;58(10):e00358-20.

9. Manka P, Verheyen J, Gerken G, Canbay A. Liver Failure due to Acute Viral Hepatitis (A-E). Visc Med. 2016;32(2):80-85.

10. Jiang W, Muhammad F, Ma P, Liu X, Long G. Sofosbuvir inhibits hepatitis A virus replication in vitro assessed by a cell-based fluorescent reporter system. Antiviral Res. 2018;154:51-57.

11. Nelson NP, Link-Gelles R, Hofmeister MG, Romero JR, Moore KL, Ward JW, Schillie SF. Update: recommendations of the advisory committee on immunization practices for use of hepatitis A vaccine for postexposure prophylaxis and for preexposure prophylaxis for international travel. MMWR Morb Mortal Wkly Rep. 2018;67(43):1216-1220.

12. Link-Gelles R, Hofmeister MG, Nelson NP. Use of hepatitis A vaccine for post-exposure prophylaxis in individuals over 40years of age: A systematic review of published studies and recommendations for vaccine use. Vaccine. 2018;36(20):2745-2750.

13. Paik JM, Younossi Y, Henry L, Mishra A, Younossi ZM. Recent trends in the global burden of hepatitis B virus: 20072017. Gastroenterology. 2021;160(5):1845-1846 e11843.

14. Thomas DL. Global elimination of chronic hepatitis. N Engl J Med. 2019;380(21):2041-2050. 
15. Ward JW, Hinman AR. What is needed to eliminate hepatitis B virus and hepatitis $\mathrm{C}$ virus as global health threats. Gastroenterology. 2019;156(2):297-310.

16. Testoni B, Lebosse F, Scholtes C, Berby F, Miaglia C, Subic M, Loglio A, et al. Serum hepatitis B core-related antigen (HBcrAg) correlates with covalently closed circular DNA transcriptional activity in chronic hepatitis B patients. J Hepatol. 2019;70(4):615-625.

17. Chevaliez S, Pawlotsky JM. New virological tools for screening, diagnosis and monitoring of hepatitis B and C in resource-limited settings. J Hepatol. 2018;69(4):916926.

18. Jeng WJ, Lok AS. Should treatment indications for chronic hepatitis B be expanded? Clin Gastroenterol Hepatol. 2020.

19. Chan HL, Fung S, Seto WK, Chuang WL, Chen CY, Kim HJ, Hui AJ, et al. Tenofovir alafenamide versus tenofovir disoproxil fumarate for the treatment of $\mathrm{HBeAg}$-positive chronic hepatitis B virus infection: a randomised, doubleblind, phase 3, non-inferiority trial. Lancet Gastroenterol Hepatol. 2016;1(3):185-195.

20. Agarwal K, Brunetto M, Seto WK, Lim YS, Fung S, Marcellin $\mathrm{P}, \mathrm{Ahn} \mathrm{SH}$, et al. 96weeks treatment of tenofovir alafenamide vs. tenofovir disoproxil fumarate for hepatitis B virus infection. J Hepatol. 2018;68(4):672-681.

21. Terrault NA, Bzowej NH, Chang KM, Hwang JP, Jonas MM, Murad MH, American Association for the Study of Liver D. AASLD guidelines for treatment of chronic hepatitis B. Hepatology. 2016;63(1):261-283.

22. Terrault NA, Lok ASF, McMahon BJ, Chang KM, Hwang JP, Jonas MM, Brown RS, Jr., et al. Update on prevention, diagnosis, and treatment of chronic hepatitis B: AASLD 2018 hepatitis B guidance. Hepatology. 2018;67(4):15601599.

23. European Association for the Study of the Liver. EASL 2017 Clinical Practice Guidelines on the management of hepatitis B virus infection. J Hepatol. 2017;67(2):370398.

24. Cornberg M, Lok AS, Terrault NA, Zoulim F, Faculty E-AHTEC. Guidance for design and endpoints of clinical trials in chronic hepatitis B - Report from the 2019 EASL-AASLD HBV Treatment Endpoints Conference. Hepatology. 2019.

25. Fanning GC, Zoulim F, Hou J, Bertoletti A. Therapeutic strategies for hepatitis B virus infection: towards a cure. Nat Rev Drug Discov. 2019;18(11):827-844.

26. Suk-Fong Lok A. Hepatitis B treatment: what we know now and what remains to be researched. Hepatol Commun. 2019;3(1):8-19.

27. Lok AS, Zoulim F, Dusheiko G, Ghany MG. Hepatitis B cure: From discovery to regulatory approval. Hepatology. 2017;66(4):1296-1313.

28. van den Berg F, Limani SW, Mnyandu N, Maepa MB, Ely A, Arbuthnot P. Advances with RNAi-Based Therapy for Hepatitis B Virus Infection. Viruses. 2020;12(8).

29. Yuen MF, Schiefke I, Yoon JH, Ahn SH, Heo J, Kim JH, Lik Yuen Chan H, et al. RNA interference therapy with ARC-520 results in prolonged hepatitis b surface antigen response in patients with chronic hepatitis B infection.
Hepatology. 2020;72(1):19-31.

30. Gane EJL S, Lim TH, Strasser S, Sievert W, Cheng W, Thompson A, Given B, et al. First results with rna interference (rnai) in chronic hepatitis b (chb) using AROHBV. Hepatology. 2018;68:1463A.

31. Han K, Cremer J, Elston R, Oliver S, Baptiste-Brown S, Chen S, Gardiner D, et al. A randomized, double-blind, placebo-controlled, first-time-in-human study to assess the safety, tolerability, and pharmacokinetics of single and multiple ascending doses of GSK3389404 in healthy subjects. Clin Pharmacol Drug Dev. 2019;8(6):790-801.

32. Yuen R, Heo J, Kumada H, Suzuki F, Suzuki Y, Xie Q, Jia J, et al. Results after 12 weeks treatment of multiple doses of GSK3389404 in chronic hepatitis B (CHB) subjects on stable nucleos (t) ide therapy in a phase 2 a doubleblind, placebo-controlled study. Poster abstract, AASLD The Liver Meeting, Boston, USA, November 9-13 2019. Hepatoogy. 2019.

33. Gane E, Yuen M-F, Bo Q, Schwabe C, Tanwandee T, Das S, Jin Y, et al. FRI-219-RO7049389, a core protein allosteric modulator, demonstrates robust decline in HBV DNA and HBV RNA in chronic HBV infected patients. J Hepatol. 2019;70:E491.

34. Yuen MF, Agarwal K, Gane EJ, Schwabe C, Ahn SH, Kim DJ, Lim YS, et al. Safety, pharmacokinetics, and antiviral effects of ABI-H0731, a hepatitis B virus core inhibitor: a randomised, placebo-controlled phase 1 trial. Lancet Gastroenterol Hepatol. 2020;5(2):152-166.

35. Zoulim F, Lenz O, Vandenbossche JJ, Talloen W, Verbinnen T, Moscalu I, Streinu-Cercel A, et al. JNJ-56136379, an HBV capsid assembly modulator, is well-tolerated and has antiviral activity in a phase 1 study of patients with chronic infection. Gastroenterology. 2020;159(2):521533 e 529.

36. Yuen M-FL S, Given B, Schluep T, Hamilton J, Biermer M, Kalmeijer R, Beumont M, et al. First clinical experience with RNA interference-based triple combination therapy in chronic hepatitis B: JNJ-3989, JNJ-6379 and a Nucleos (t) ide analogue. Hepatology. 2019;70:1489A.

37. Weldemeyer H SK, Bogomolov P, Voronka N, Stepanova T, Bremer B, Alweiss L, Dandri M, et al. Final results of a multicenter open lebel phase 2 clinical trial (MYR203) to assess safety and efficacy of Myrcludex B with Peg interferon a-2a in Patients with Chronic Hepatitis HBV/ HDV Co-Infection. J Hepatol. 2019;70:e81.

38. Schoneweis K, Motter N, Roppert PL, Lu M, Wang B, Roehl I, Glebe D, et al. Activity of nucleic acid polymers in rodent models of HBV infection. Antiviral Res. 2018;149:26-33.

39. Bazinet M, Pantea V, Placinta G, Moscalu I, Cebotarescu V, Cojuhari L, Jimbei P, et al. Safety and efficacy of 48 weeks REP 2139 or REP 2165, tenofovir disoproxil, and pegylated interferon Alfa-2a in patients with chronic HBV infection naive to nucleos(t)ide Therapy. Gastroenterology. 2020;158(8):2180-2194.

40. Lee HW, Park JY, Hong T, Park MS, Ahn SH. Efficacy of lenvervimab, a recombinant human immunoglobulin, in treatment of chronic hepatitis B virus infection. Clin Gastroenterol Hepatol. 2020;18(13):3043-3045 e3041. 
41. Janssen HLA, Brunetto MR, Kim YJ, Ferrari C, Massetto B, Nguyen AH, Joshi A, et al. Safety, efficacy and pharmacodynamics of vesatolimod (GS-9620) in virally suppressed patients with chronic hepatitis B. J Hepatol. 2018;68(3):431-440.

42. Edward Gane PRD, Anna Brooks, Yang Zhao, Susanna Tan, Audrey Lau, Jenny Yang, Anuj Gaggar, et al. Efficacy and safety of 24 weeks treatment with oral TLR8 agonist, selgantolimod, in virallysuppressed adult patients with chronic hepatitis B: a phase 2 study. J Hepatol. 2020:AS071.

43. Janssen Y-SL HL, Kim HJ, Tseng CH, Coffin CS, Elkashab M, Anh SH, Nguyen AH, et al. Safety and efficacy of 24 weeks of treatment with oral TLR8 agonist selgantolimod in viremic adult patients with chronic hepatitis B: a phase 2 study. Hepatology. 2020.

44. Yuen RC, Liu CY, Jeng CJ, Elkhashab RWJ, Coffin M, Kim C, Greenbloom W, et al. Ascending dose cohort study of inarigivir - A novel RIG I agonist in chronic HBV patients: Final results of the ACHIEVE trial. J Hepatol. 2019;170(1):e47-e48.

45. Boni C, Janssen HLA, Rossi M, Yoon SK, Vecchi A, Barili V, Yoshida EM, et al. Combined GS-4774 and tenofovir therapy can improve HBV-specific T-cell responses in patients with chronic hepatitis. Gastroenterology. 2019;157(1):227-241 e227.

46. Zoulim F, Fournier C, Habersetzer F, Sprinzl M, Pol S, Coffin CS, Leroy V, et al. Safety and immunogenicity of the therapeutic vaccine TG1050 in chronic hepatitis B patients: a phase 1b placebo-controlled trial. Hum Vaccin Immunother. 2020;16(2):388-399.

47. Fisicaro P, Valdatta C, Massari M, Loggi E, Biasini E, Sacchelli L, Cavallo MC, et al. Antiviral intrahepatic Tcell responses can be restored by blocking programmed death-1 pathway in chronic hepatitis B. Gastroenterology. 2010;138(2):682-693, e681-684.

48. Gane E, Verdon DJ, Brooks AE, Gaggar A, Nguyen AH, Subramanian GM, Schwabe C, et al. Anti-PD-1 blockade with nivolumab with and without therapeutic vaccination for virally suppressed chronic hepatitis B: A pilot study. J Hepatol. 2019;71:900-907.

49. Petruzziello A, Marigliano S, Loquercio G, Cozzolino A, Cacciapuoti C. Global epidemiology of hepatitis $\mathrm{C}$ virus infection: An up-date of the distribution and circulation of hepatitis C virus genotypes. World J Gastroenterol. 2016;22(34):7824-7840.

50. Spearman CW, Dusheiko GM, Hellard M, Sonderup M. Hepatitis C. Lancet. 2019;394(10207):1451-1466.

51. Calvaruso V, Petta S, Craxi A. Is global elimination of HCV realistic? Liver Int. 2018;38(Suppl 1):40-46.

52. Aasld Idsa Hcv Guidance Panel. Hepatitis C guidance: AASLD-IDSA recommendations for testing, managing, and treating adults infected with hepatitis $\mathrm{C}$ virus. Hepatology. 2015;62(3):932-954.

53. Chevaliez S, Soulier A, Poiteau L, Bouvier-Alias M, Pawlotsky JM. Clinical utility of hepatitis $\mathrm{C}$ virus core antigen quantification in patients with chronic hepatitis C. J Clin Virol. 2014;61(1):145-148.

54. Poiteau L, Soulier A, Lemoine M, Mohammed Z, Wlas- sow M, Rwegasha J, Pawlotsky JM, et al. Performance of a new rapid diagnostic test for the detection of antibodies to hepatitis C virus. J Virol Methods. 2018;261:153-155.

55. Laursen TL, Sandahl TD, Kazankov K, George J, Gronbaek H. Liver-related effects of chronic hepatitis C antiviral treatment. World J Gastroenterol. 2020;26(22):29312947.

56. Chung RT, Gale M, Jr., Polyak SJ, Lemon SM, Liang TJ, Hoofnagle JH. Mechanisms of action of interferon and ribavirin in chronic hepatitis C: Summary of a workshop. Hepatology. 2008;47(1):306-320.

57. Palumbo E. Pegylated interferon and ribavirin treatment for hepatitis $\mathrm{C}$ virus infection. Ther Adv Chronic Dis. 2011;2(1):39-45.

58. (IDSA). AAftSoLDAaIDSoA. HCV guidance: recommendations for testing, managing, and treating hepatitis C, vol. 2021. American Association for the Study of Liver Diseases (AASLD) and Infectious Diseases Society of America (IDSA). 2021.

59. Moradpour D, Penin F. Hepatitis C virus proteins: from structure to function. Curr Top Microbiol Immunol. 2013;369:113-142.

60. Ahmed M. Era of direct acting anti-viral agents for the treatment of hepatitis C. World J Hepatol. 2018;10(10):670-684.

61. Carrat F, Fontaine H, Dorival C, Simony M, Diallo A, Hezode C, De Ledinghen V, et al. Clinical outcomes in patients with chronic hepatitis $\mathrm{C}$ after direct-acting antiviral treatment: a prospective cohort study. Lancet. 2019;393(10179):1453-1464.

62. Pawlotsky JM. NS5A inhibitors in the treatment of hepatitis C. J Hepatol. 2013;59(2):375-382.

63. Ghany MG, Morgan TR, Aasld-Idsa Hepatitis C Guidance Panel. Hepatitis C guidance 2019 update: American Association for the study of liver diseases-infectious diseases society of america recommendations for testing, managing, and treating hepatitis $\mathrm{C}$ virus infection. Hepatology. 2020;71(2):686-721.

64. Degenhardt L, Peacock A, Colledge S, Leung J, Grebely J, Vickerman P, Stone J, et al. Global prevalence of injecting drug use and sociodemographic characteristics and prevalence of $\mathrm{HIV}, \mathrm{HBV}$, and $\mathrm{HCV}$ in people who inject drugs: a multistage systematic review. Lancet Glob Health. 2017;5(12):e1192-e1207.

65. Karimi SE, Bayani A, Higgs P, Bayat AH, Hemmat M, Ahounbar E, Armoon B, et al. Prevalence and high risk behaviours associated with HCV testing among people who inject drugs: a systematic review and Meta-analysis. Subst Abuse Treat Prev Policy. 2020;15(1):64.

66. Larney S, Kopinski H, Beckwith CG, Zaller ND, Jarlais DD, Hagan H, Rich JD, et al. Incidence and prevalence of hepatitis $\mathrm{C}$ in prisons and other closed settings: results of a systematic review and meta-analysis. Hepatology. 2013;58(4):1215-1224.

67. Pedrana A, Howell J, Scott N, Schroeder S, Kuschel C, Lazarus JV, Atun R, et al. Global hepatitis C elimination: an investment framework. Lancet Gastroenterol Hepatol. 2020;5(10):927-939.

68. McGowan CE, Fried MW. Barriers to hepatitis C treat- 
ment. Liver Int. 2012;32(Suppl 1):151-156.

69. Platt L, Easterbrook P, Gower E, McDonald B, Sabin K, McGowan C, Yanny I, et al. Prevalence and burden of HCV co-infection in people living with HIV: a global systematic review and meta-analysis. Lancet Infect Dis. 2016;16(7):797-808.

70. Schlabe S, Rockstroh JK. Advances in the treatment of HIV/HCV coinfection in adults. Expert Opin Pharmacother. 2018;19(1):49-64.

71. Meissner EG. Update in HIV-hepatitis C virus coinfection in the direct acting antiviral era. Curr Opin Gastroenterol. 2017;33(3):120-127.

72. Pol S, Parlati L, Jadoul M. Hepatitis C virus and the kidney. Nat Rev Nephrol. 2019;15(2):73-86.

73. Aasld-Idsa Hcv Guidance Panel. Hepatitis C guidance 2018 update: AASLD-IDSA recommendations for testing, managing, and treating hepatitis $\mathrm{C}$ virus infection. Clin Infect Dis. 2018;67(10):1477-1492.

74. Khan MU, Mahmoud MI, Butt AA. Hepatitis c virus and chronic kidney disease. Expert Rev Gastroenterol Hepatol. 2020;14(7):579-590.

75. Gordon CE, Berenguer MC, Doss W, Fabrizi F, Izopet J, Jha V, Kamar N, et al. Prevention, diagnosis, evaluation, and treatment of hepatitis $\mathrm{c}$ virus infection in chronic kidney disease: synopsis of the kidney disease: improving global outcomes 2018 clinical practice guideline. Ann Intern Med. 2019;171(7):496-504.

76. Kanwal F, Kramer J, Asch SM, Chayanupatkul M, Cao Y, El-Serag HB. Risk of hepatocellular cancer in HCV patients treated with direct-acting antiviral agents. Gastroenterology. 2017;153(4):996-1005 e1001.

77. Romano A, Angeli P, Piovesan S, Noventa F, Anastassopoulos G, Chemello L, Cavalletto L, et al. Newly diagnosed hepatocellular carcinoma in patients with advanced hepatitis C treated with DAAs: A prospective population study. J Hepatol. 2018;69(2):345-352.

78. Kanwal F, Kramer JR, Asch SM, Cao Y, Li L, El-Serag $\mathrm{HB}$. Long-term risk of hepatocellular carcinoma in HCV patients treated with direct acting antiviral agents. Hepatology. 2020;71(1):44-55.

79. Axley P, Ahmed Z, Ravi S, Singal AK. Hepatitis C virus and hepatocellular carcinoma: a narrative review. J Clin Transl Hepatol. 2018;6(1):79-84.

80. Kondili LA, Gaeta GB, Brunetto MR, Di Leo A, Iannone A, Santantonio TA, Giammario A, et al. Incidence of DAA failure and the clinical impact of retreatment in real-life patients treated in the advanced stage of liver disease: Interim evaluations from the PITER network. PLoS One. 2017;12(10):e0185728.

81. Wyles DL, Luetkemeyer AF. Understanding hepatitis C virus drug resistance: clinical implications for current and future regimens. Top Antivir Med. 2017;25(3):103-109.

82. Welker MW, Luhne S, Lange CM, Vermehren J, Farnik H, Herrmann E, Welzel T, et al. Lactic acidosis in patients with hepatitis $\mathrm{C}$ virus cirrhosis and combined ribavirin/ sofosbuvir treatment. J Hepatol. 2016;64(4):790-799.

83. Renard S, Borentain P, Salaun E, Benhaourech S, Maille B, Darque A, Bregigeon S, et al. Severe Pulmonary Arterial Hypertension in Patients Treated for Hepatitis C With
Sofosbuvir. Chest. 2016;149(3):e69-73.

84. Cachay ER, Mena A, Morano L, Benitez L, Maida I, Ballard C, Hill L, et al. Predictors of hepatitis C treatment failure after using direct-acting antivirals in people living with human immunodeficiency virus. Open Forum Infect Dis. 2019;6(3):ofz070.

85. Belli LS, Perricone G, Adam R, Cortesi PA, Strazzabosco M, Facchetti R, Karam V, et al. Impact of DAAs on liver transplantation: Major effects on the evolution of indications and results. An ELITA study based on the ELTR registry. J Hepatol. 2018;69(4):810-817.

86. Bohorquez H, Bugeaud E, Bzowej N, Scheuermann J, Hand J, Bruce D, Carmody I, et al. Liver transplantation using hepatitis $C$ virus-viremic donors into hepatitis $\mathrm{C}$ virus-aviremic recipients as standard of care. Liver Transpl. 2021;27(4):548-557.

87. Chhatwal J, Samur S, Kues B, Ayer T, Roberts MS, Kanwal F, Hur C, et al. Optimal timing of hepatitis C treatment for patients on the liver transplant waiting list. Hepatology. 2017;65(3):777-788.

88. Vukotic R, Conti F, Fagiuoli S, Morelli MC, Pasulo L, Colpani M, Foschi FG, et al. Long-term outcomes of direct acting antivirals in post-transplant advanced hepatitis $\mathrm{C}$ virus recurrence and fibrosing cholestatic hepatitis. J Viral Hepat. 2017;24(10):858-864.

89. Terrault NA, Berenguer M, Strasser SI, Gadano A, Lilly L, Samuel D, Kwo PY, et al. International liver transplantation society consensus statement on hepatitis C management in liver transplant recipients. Transplantation. 2017;101(5):956-967.

90. Ismail MS, Hassan M, Khaderi SA, Yousry WA, Kamal El-Din MM, Bahaa El-Din MM, El Sayed OA, et al. Clinical efficacy of direct-acting antiviral therapy for recurrent hepatitis $\mathrm{C}$ virus infection after liver transplantation in patients with hepatocellular carcinoma. World J Hepatol. 2020;12(9):628-640.

91. Cieciura T, Hryniewiecka E, Foroncewicz B, Strzelczyk Z, Ciszek M, Paczek L. Long-term follow-up of liver transplant recipients treated with direct-acting antiviral agents for hepatitis $\mathrm{C}$ recurrence after transplantation. Transplant Proc. 2020;52(8):2468-2471.

92. Cotter TG, Paul S, Sandikci B, Couri T, Bodzin AS, Little EC, Sundaram V, et al. Increasing utilization and excellent initial outcomes following liver transplant of hepatitis $\mathrm{C}$ virus (HCV)-viremic donors into $\mathrm{HCV}$-negative recipients: outcomes following liver transplant of HCVviremic donors. Hepatology. 2019;69(6):2381-2395.

93. Ivanics T, Rizzari M, Moonka D, Al-Kurd A, Delvecchio K, Kitajima T, Elsabbagh AM, et al. Retransplantation outcomes for hepatitis $\mathrm{C}$ in the United States before and after direct-acting antiviral introduction. Am J Transplant. 2021;21(3):1100-1112.

94. Bhamidimarri KR, Satapathy SK, Martin P. Hepatitis C Virus and Liver Transplantation. Gastroenterol Hepatol (N Y). 2017;13(4):214-220.

95. Cholankeril G, Joseph-Talreja M, Perumpail BJ, Liu A, Yoo ER, Ahmed A, Goel A. Timing of hepatitis C Virus treatment in liver transplant candidates in the era of direct-acting antiviral agents. J Clin Transl Hepatol. 
2017;5(4):363-367.

96. Kwong AJ, Wall A, Melcher M, Wang U, Ahmed A, Subramanian A, Kwo PY. Liver transplantation for hepatitis $\mathrm{C}$ virus (HCV) non-viremic recipients with $\mathrm{HCV}$ viremic donors. Am J Transplant. 2019;19(5):1380-1387.

97. Bari K, Luckett K, Kaiser T, Diwan T, Cuffy M, Schoech MR, Safdar K, et al. Hepatitis C transmission from seropositive, nonviremic donors to non-hepatitis $\mathrm{C}$ liver transplant recipients. Hepatology. 2018;67(5):1673-1682.

98. Crespo G, Trota N, Londono MC, Mauro E, Baliellas C, Castells L, Castellote J, et al. The efficacy of direct antiHCV drugs improves early post-liver transplant survival and induces significant changes in waiting list composition. J Hepatol. 2018;69(1):11-17.

99. Hellard ME, Chou R, Easterbrook P. WHO guidelines on testing for hepatitis $\mathrm{B}$ and $\mathrm{C}$ - meeting targets for testing. BMC Infect Dis. 2017;17(Suppl 1):703.

100. Thrift AP, El-Serag HB, Kanwal F. Global epidemiology and burden of HCV infection and HCV-related disease. Nat Rev Gastroenterol Hepatol. 2017;14(2):122-132.

101. Dore GJ, Bajis S. Hepatitis C virus elimination: laying the foundation for achieving 2030 targets. Nat Rev Gastroenterol Hepatol. 2021;18(2):91-92.

102. Cooke GS, Andrieux-Meyer I, Applegate TL, Atun R, Burry JR, Cheinquer H, Dusheiko G, et al. Accelerating the elimination of viral hepatitis: a Lancet Gastroenterology \& Hepatology Commission. Lancet Gastroenterol Hepatol. 2019;4(2):135-184.

103. Smith S, Harmanci H, Hutin Y, Hess S, Bulterys M, Peck $\mathrm{R}$, Rewari B, et al. Global progress on the elimination of viral hepatitis as a major public health threat: An analysis of WHO Member State responses 2017. JHEP Rep. 2019;1(2):81-89.

104. Waked I, Esmat G, Elsharkawy A, El-Serafy M, AbdelRazek W, Ghalab R, Elshishiney G, et al. Screening and treatment program to eliminate hepatitis C in Egypt. N Engl J Med. 2020;382(12):1166-1174.

105. Fourati S, Feld JJ, Chevaliez S, Luhmann N. Approaches for simplified HCV diagnostic algorithms. J Int AIDS Soc. 2018;21(Suppl 2):e25058.

106. Stockdale AJ, Kreuels B, Henrion MYR, Giorgi E, Kyomuhangi I, de Martel C, Hutin Y, et al. The global prevalence of hepatitis D virus infection: Systematic review and meta-analysis. J Hepatol. 2020;73(3):523-532.

107. Gilman C, Heller T, Koh C. Chronic hepatitis delta: A state-of-the-art review and new therapies. World J Gastroenterol. 2019;25(32):4580-4597.

108. Kushner T, Serper M, Kaplan DE. Delta hepatitis within the Veterans Affairs medical system in the United States: Prevalence, risk factors, and outcomes. J Hepatol. 2015;63(3):586-592.

109. Kang C, Syed YY. Bulevirtide: First Approval. Drugs. 2020;80(15):1601-1605.

110. European-Medicines-Agency. Hepcludex (bulevirtide) powder for solution for injection: EU summary of product characteristics. European-Medicines-Agency. 2020.

111. Wedemeyer H, Yurdaydin C, Dalekos GN, Erhardt A, Cakaloglu Y, Degertekin H, Gurel S, et al. Peginterferon plus adefovir versus either drug alone for hepatitis delta.
N Engl J Med. 2011;364(4):322-331.

112. Wedemeyer H, Yurdaydin C, Hardtke S, Caruntu FA, Curescu MG, Yalcin K, Akarca US, et al. Peginterferon alfa-2a plus tenofovir disoproxil fumarate for hepatitis D (HIDIT-II): a randomised, placebo controlled, phase 2 trial. Lancet Infect Dis. 2019;19(3):275-286.

113. Yurdaydin C, Keskin O, Kalkan C, Karakaya F, Caliskan A, Karatayli E, Karatayli S, et al. Optimizing lonafarnib treatment for the management of chronic delta hepatitis: The LOWR HDV-1 study. Hepatology. 2018;67(4):12241236.

114. Etzion O HS, Lurie Y, et al. End of study results from LIMT HDV study: 36\% durable virologic response at 24 weeks post-treatment with pegylated interferon lambda monotherapy in patients with chronic hepatitis delta virus infection. J Hepatol. 2019;70(1):e32.

115. Bazinet M, Pantea V, Cebotarescu V, Cojuhari L, Jimbei P, Albrecht J, Schmid P, et al. Safety and efficacy of REP 2139 and pegylated interferon alfa-2a for treatment-naive patients with chronic hepatitis B virus and hepatitis D virus co-infection (REP 301 and REP 301-LTF): a non-randomised, open-label, phase 2 trial. Lancet Gastroenterol Hepatol. 2017;2(12):877-889.

116. Nimgaonkar I, Ding Q, Schwartz RE, Ploss A. Hepatitis E virus: advances and challenges. Nat Rev Gastroenterol Hepatol. 2018;15(2):96-110.

117. Chionne P, Madonna E, Pisani G, Taffon S, La Rosa G, Candido A, Dettori S, et al. Evaluation of rapid tests for diagnosis of acute hepatitis E. J Clin Virol. 2016;78:4-8.

118. Pisanic N, Rahman A, Saha SK, Labrique AB, Nelson KE, Granger DA, Granger SW, et al. Development of an oral fluid immunoassay to assess past and recent hepatitis E virus (HEV) infection. J Immunol Methods. 2017;448:18.

119. Lhomme S, Marion O, Abravanel F, Izopet J, Kamar N. Clinical manifestations, pathogenesis and treatment of hepatitis E virus infections. J Clin Med. 2020;9(2).

120. Berglov A, Hallager S, Weis N. Hepatitis E during pregnancy: Maternal and foetal case-fatality rates and adverse outcomes-A systematic review. J Viral Hepat. 2019;26(11):1240-1248.

121. Gouilly J, Chen Q, Siewiera J, Cartron G, Levy C, Dubois M, Al-Daccak R, et al. Genotype specific pathogenicity of hepatitis E virus at the human maternal-fetal interface. Nat Commun. 2018;9(1):4748.

122. Jilani N, Das BC, Husain SA, Baweja UK, Chattopadhya D, Gupta RK, Sardana S, et al. Hepatitis E virus infection and fulminant hepatic failure during pregnancy. J Gastroenterol Hepatol. 2007;22(5):676-682.

123. Kar P, Sengupta A. A guide to the management of hepatitis E infection during pregnancy. Expert Rev Gastroenterol Hepatol. 2019;13(3):205-211.

124. European Association for the Study of the Liver. Electronic address, easloffice@easloffice.eu.EASL Clinical Practice Guidelines on hepatitis E virus infection. J Hepatol. 2018;68(6):1256-1271.

125. Kamar N, Garrouste C, Haagsma EB, Garrigue V, Pischke S, Chauvet C, Dumortier J, et al. Factors associated with chronic hepatitis in patients with hepatitis $\mathrm{E}$ virus 
infection who have received solid organ transplants. Gastroenterology. 2011;140(5):1481-1489.

126. Kamar N, Izopet J, Tripon S, Bismuth M, Hillaire S, Dumortier J, Radenne S, et al. Ribavirin for chronic hepatitis $\mathrm{E}$ virus infection in transplant recipients. N Engl J Med. 2014;370(12):1111-1120.

127. Kamar N, Rostaing L, Abravanel F, Garrouste C, Esposito L, Cardeau-Desangles I, Mansuy JM, et al. Pegylated interferon-alpha for treating chronic hepatitis $\mathrm{E}$ virus infection after liver transplantation. Clin Infect Dis. 2010;50(5):e30-33.

128. Haagsma EB, Riezebos-Brilman A, van den Berg AP, Porte RJ, Niesters HG. Treatment of chronic hepatitis E in liver transplant recipients with pegylated interferon alpha-2b. Liver Transpl. 2010;16(4):474-477.

129. van der Valk M, Zaaijer HL, Kater AP, Schinkel J. Sofosbuvir shows antiviral activity in a patient with chronic hepatitis E virus infection. J Hepatol. 2017;66(1):242243.

130. van Wezel EM, de Bruijne J, Damman K, Bijmolen M, van den Berg AP, Verschuuren EAM, Ruigrok GA, et al. Sofosbuvir add-on to ribavirin treatment for chronic hepatitis E virus infection in solid organ transplant recipients does not result in sustained virological response. Open Forum Infect Dis. 2019;6(8).

131. Todesco E, Demeret S, Calin R, Roque-Afonso AM, Thibault V, Mallet V, Akhavan S, et al. Chronic hepatitis $\mathrm{E}$ in $\mathrm{HIV} / \mathrm{HBV}$ coinfected patient: lack of power of sofosbuvir-ribavirin. AIDS. 2017;31(9):1346-1348.

132. Netzler NE, Enosi Tuipulotu D, Vasudevan SG, Mackenzie JM, White PA. Antiviral Candidates for Treating Hepatitis E Virus Infection. Antimicrob Agents Chemother. 2019;63(6).
133. Zhu FC, Zhang J, Zhang XF, Zhou C, Wang ZZ, Huang SJ, Wang $\mathrm{H}$, et al. Efficacy and safety of a recombinant hepatitis $\mathrm{E}$ vaccine in healthy adults: a large-scale, randomised, double-blind placebo-controlled, phase 3 trial. Lancet. 2010;376(9744):895-902.

134. Zaman K, Dudman S, Stene-Johansen K, Qadri F, Yunus M, Sandbu S, Gurley ES, et al. HEV study protocol : design of a cluster-randomised, blinded trial to assess the safety, immunogenicity and effectiveness of the hepatitis E vaccine HEV 239 (Hecolin) in women of childbearing age in rural Bangladesh. BMJ Open. 2020;10(1):e033702.

135. Yu XY, Chen ZP, Wang SY, Pan HR, Wang ZF, Zhang QF, Shen LZ, et al. Safety and immunogenicity of hepatitis E vaccine in elderly people older than 65years. Vaccine. 2019;37(32):4581-4586.

136. Reshetnyak VI, Karlovich TI, Ilchenko LU. Hepatitis G virus. World J Gastroenterol. 2008;14(30):4725-4734.

137. Marano G, Franchini M, Farina B, Piccinini V, Pupella S, Vaglio S, Grazzini G, et al. The human pegivirus: A new name for an "ancient" virus. Can transfusion medicine come up with something new? Acta Virol. 2017;61(4):401412.

138. Bhattarai N, Stapleton JT. GB virus C: the good boy virus? Trends Microbiol. 2012;20(3):124-130.

139. Liu Z, Zhang Y, Wei F, Xu M, Mou D, Zhang T, Li W, et al. Detection of GB virus $\mathrm{C}$ genomic sequence in the cerebrospinal fluid of a HIV-infected patient in China: a case report and literature review. Epidemiol Infect. 2016;144(1):106-112.

140. Wang T, Chen J, Zhang Q, Huang X, Xie N, Zhang J, Cai $\mathrm{T}$, et al. Prevalence of hepatitis $\mathrm{G}$ virus infection among 67,348 blood donors in mainland China. BMC Public Health. 2019;19(1):685. 